\title{
6 Disease concepts and classifications in ancient Mesopotamian medicine
}

\author{
Ulrike Steinert
}

\section{Introduction}

The cross-cultural variability of disease concepts, categories and the social embeddedness of individuals' experiences of health and illness have often been emphasised in medical anthropology and have been contrasted with diseases as delimited and defined by biomedicine. ${ }^{1}$ However, ongoing debates in the historical disciplines concerning the applicability and feasibility of retrospective diagnoses to ancient texts show that the question of compatibility of ancient and modern nosological concepts is also virulent in the history of medicine. ${ }^{2}$ In Assyriological research concerned with medical texts cuneiform, different approaches have been advanced to analyse and interpret the textual sources. Throughout earlier work in the twentieth century and up to recent publications, an etic approach has dominated, aimed at finding equations between ancient and modern biomedical disease categories and describing Mesopotamian medicine in terms of our own classificatory system (e.g. Köcher 1986; Kinnier Wilson 1994; Biggs 1991; Geller and Cohen 1995; Scurlock and Andersen 2005; Haussperger 2012). This approach has received much criticism in recent years but is still applied, although the methodological problems and speculative nature of retrospective diagnoses are likewise recognised. ${ }^{3}$ The inherent problem of this approach is that it builds on the assumption that human biology and physiology have not changed since antiquity and that morbid conditions should not have changed either because they have a universal biological basis. However, historical and anthropological work have demonstrated that biological (and epidemiological) processes are subject to local variation and that conceptualisations, definitions, classifications and experiences of sickness are culturally and socially shaped and thus undergo historical changes. ${ }^{4}$

Some Assyriological studies have applied comparative approaches to elucidate Mesopotamian disease concepts through cross-cultural parallels and comparisons (e.g. Stol 1993 on epilepsy; Stol 2000 on childbirth; Steinert 2013 on women's conditions). The steady progress made in recent decades in publishing and editing the textual material has furthered emic approaches aiming at uncovering the systematics and cultural embeddedness of Mesopotamian disease concepts and categories on the basis of their own inherent logic and imagery (see e.g. Geller 2005; Böck 2014; Steinert 2016; Bácskay 2017), an approach which is also followed here. 
Mesopotamian medical texts present a considerable but delimited corpus of more than a thousand tablets and fragments which can be divided into several different genres or text types. These can be more or less clearly assigned to the two main healing professions in Mesopotamia, attested from the third to the first millennium BCE: the 'conjurer/exorcist; ritual specialist; healer' (āšipu/mašmaššsu) and the 'physician' (aŝ)..$^{5}$ The textual material reflects a variety of techniques and approaches to illness, health and healing, which combine empirical, technical and rational elements with religious, magical and ethical components. Thus, Mesopotamian medicine could be regarded as a holistic system of healing, taking into account the patient, his/her body, behaviour, actions, socio-economic situation and relations with the environment - an environment which was also inhabited by powerful beings such as gods, demons or the ghosts of the deceased, all of which were recognised as agents causing sickness or misfortune as much as wealth and well-being. ${ }^{6}$ Depending on the context and perceived cause of an illness, healing not only involved medical therapies that aimed at curing symptoms, but could also include ritual actions, prayers or offerings aimed at normalising a disturbed relationship between the patient and the social/divine world, regarded as the deeper cause of the patient's suffering.

The first group of sources at our disposal are the diagnostic texts, which present collections of symptom descriptions with a diagnosis and/or prognosis, but usually do not contain therapeutic instructions, and which are attested from the Old Babylonian period (the first half of the second millennium) to the last centuries of the first millennium BCE (Late Babylonian period). ${ }^{7}$

The second text group are the therapeutic texts, which can be divided into the genres of medical recipes, incantations and rituals. ${ }^{8}$ While incantations started to be written down already early in the third millennium, the first medical prescriptions are known from the Ur-III and Old Babylonian period (at the end of the third and beginning of the second millennium). Both genres are usually not intermixed in the text sources of these early periods, although tablets with incantations can feature short ritual instructions supplementing the text of the spells. ${ }^{9}$ In later periods, one regularly encounters therapeutic tablets that combine sections of prescriptions with incantations, because in practice medical treatments were regularly combined with the recitation of a spell in order to render the remedy more effective. However, it is still common to find medical tablets from the late periods that lack incantations (and vice versa; there are also collections of healing spells without prescriptions).

Another considerable group of texts are drug compendia (attested from the third to the first millennium), which can be lists of materia medica (plants, minerals, animal substances); therapeutic vademecums listing the names, therapeutic uses and application forms of drugs; or plant/stone description texts. ${ }^{10}$ Furthermore, from the first millennium BCE, medical commentaries (on diagnostic/therapeutic texts) are preserved, which had important functions as scholarly tools for teaching and study, providing explanations and interpretations on the meanings and readings of specific terms and phrases encountered in the source texts. ${ }^{11}$

The majority of the preserved sources date to the first millennium BCE and can be divided into Assyrian and Babylonian texts, referring to the ductus of the 
script, geographic provenience (from Assyria in the north or Babylonia in the south of the Mesopotamian heartland) and dialectal peculiarities. ${ }^{12}$ Fewer texts have been recovered from peripheral regions (such as the Levantine coast and Asia Minor). The ductus of the script often provides a major clue for determining the period from which a given cuneiform tablet stems, but often texts cannot be dated exactly, for instance if a tablet lacks a colophon providing a date or if no archaeological context is known. ${ }^{13}$ It should also be added that cuneiform texts such as incantations or recipes were often transmitted over long periods of time, although often not in identical form: incantations may become reshaped or extended; new or variant spells were composed based on an existing model; and collections of material such as medical prescriptions may undergo processes of editing, extension, fusion or compilation.

It is also noteworthy that the formats of the medical tablets at our disposal reflect different contexts of use that these texts once had. Thus, a part of the texts can be identified as excerpts or shorter extracts of varying length, which are usually inscribed on smaller one-column tablets and were used either as school texts (written by students) or for practical application (e.g. recipes used for a specific patient or protective amulets inscribed with a spell and hung up in the client's house). ${ }^{14} \mathrm{~A}$ second group of medical texts can be loosely designated as collections of related material, which are typically inscribed on multi-column tablets. These collections of related materials can belong to medical compendia, which had functions as scholarly reference works or teaching manuals. Such collections can range from recipe collections to treatises covering one or multiple topics. ${ }^{15}$

Although multi-column tablets with text collections (especially of incantations) were already compiled in the third millennium, especially during the end of the second and in the first millennium BCE, different variant textual traditions were shaped into diagnostic and therapeutic series with a fixed structure - a process called 'serialisation' (or 'canonisation'), which can be observed in various branches of scholarly and technical literature (such as omen collections, incantations/ritual texts and medical literature).${ }^{16}$ From a diachronic perspective, there are certain stable elements with regard to textual genres, compositions and medical practices (the so-called stream of tradition), but there are also elements of change, innovation and evolution within the healing disciplines and their text corpora.

\section{The structure of diagnostic and therapeutic entries}

Medical cuneiform tablets usually consist of several text sections which are marked visually by rulings separating them and aiding the retrieval of information. Ruled-off text sections form units of content, which can contain e.g. the text of an incantation, a ritual instruction, one or several related prescriptions for a specific purpose or a group of related diagnostic entries. The entries or textual units ('cases'), of which diagnostic and therapeutic texts (especially medical 
recipes) consist, have a common structure. Both diagnostic and therapeutic texts typically begin with a symptom description followed by a diagnosis, which are formulated in casuistic form ('If $\mathrm{X}$, then $\mathrm{Y}$ '). ${ }^{17}$ Diagnostic texts usually focus on listing symptoms and on identifying the ailment or, more often, the causative agent responsible for the problem. Their typical structure consists of symptom description, diagnosis and prognosis, the latter of which can be positive ('he/she will recover'), negative ('he/she will die', 'he/she will not recover'), protracted ('his illness will be of long duration/is severe', 'he will first recover but then (the condition) will change and he will die') or undecided ('the āšipu shall not make a prognosis for his recovery').$^{18}$ In addition to the causative agent, the diagnosis can include a cause referring to actions of the patient, such as moral transgressions or broken taboos, that triggered the ailment: ${ }^{19}$

\section{Diagnostic Handbook Tablet 13: 10, 31 (Scurlock 2014: 103-4, 109, 111)}

If his 'epigastrium` continually afflicts (lit. seizes) him, (it is an) affliction (lit. seizure) by a ghost. ${ }^{20}$

[...]

If his epigastrium is raised and his abdomen is hard and he gets hot and (then) cold, (his illness is due to the) 'Hand of the (personal) goddess'; he will not get well.

\section{Diagnostic Handbook Tablet 11: 1 (Scurlock 2014: 82, 86)}

If the patient's right hand hurts him, (it is due to the) 'Hand of (the sun-god) Šamaš because of a vow which he (the patient) promised; he will get well.

Medical recipes can have a more varied structure. The entries (or cases) of therapeutic texts can include both symptom description and diagnosis; in other cases, the text proceeds directly from symptoms to prescription, which generally consists of a list of ingredients and instructions for preparation and administration of the remedy. Alternatively, therapies can be introduced by a simple purpose statement or short diagnostic formulation (e.g. 'to remove fever', 'to stop bleeding'):

\footnotetext{
AMT 76/1: 4-10 (Scurlock 2006: No. 200, 2014: 490-1)

[If a man's] intestines are continually colicky, his palate continually gets 'dry', his [arms] are continually numb, he belches, he has much appetite (for food), but when [he sees it], it does not please him, ..., [his heart] is (too) depressed (for him) to speak, then the 'Hand of a ghost' pursues that man. To cure him: you crush [together] (and) sift tarmuš plant, imhur-lim plant, imhur-ešra plant, atā'išu plant, 'claw of a black dog', urnû-mint, nuhurtu plant, tiyātu plant (and) alum. He should continually drink (these drugs) either in beer or wine, and then he will get well.
} 
BAM 548 iv 2' - 3' (Scurlock 2014: 467, 469)

If a man is sick with suālu (cough), you grind 'white plant'. You have him drink it (mixed) with pressed-out oil on an [empty] stomach, and he will get well.

\section{BAM 159 vi 1-4 (Scurlock 2014: 499-501; Parys 2014: 23-4, 35 § 70)}

In order to make a man's constipated bowels move and to annihilate uršulesions (haemorrhoids): you measure out equal amounts of juniper, $k u k r u$, nuhurtu, 'horned alkali' and 'plant of life'. You boil (these plants) over a fire in beer and vinegar, filter (it), let (it) cool and pour $<$ oil $>$ on it. (Then) you pour it into his anus. 'He will have a bowel movement' and get well.

Often, a prescription concludes with a positive prognostic statement ('he will recover'). In other cases, the diagnosis includes special information of instructive nature, e.g. phrases alarming the specialist about the severity of the patient's condition ('so that his illness will not become protracted', '( $t$ )his illness is of long duration', 'you shall not make a prognosis'). ${ }^{21}$ Another significant feature of the therapeutic texts is the occurrence of 'efficacy phrases' recommending and bolstering the value of a remedy and referring back to positive practical experience of past users (e.g. '(this is) a proven/probate remedy'). ${ }^{22}$

\section{Disease aetiologies in Mesopotamian medical texts}

In ancient medical systems, disease concepts and aetiologies are often linked to world views and theories about cosmos and cosmogony held in a society. How did the Babylonians perceive and explain the origin of sickness and suffering? Different text genres reflecting on this issue provide evidence for several varying ideas and mythological explanations for the human susceptibility to illness.

Predominantly in Babylonian myths, we encounter the idea of a primordial state of the world free of sickness and any kind of trouble or suffering - in these texts, diseases come into being by the conscious or accidental actions of the gods. One example is found in the Sumerian myth Enki and Ninhursag (lines 11-28):

In Dilmun, the raven was not yet cawing, the partridge not cackling. The lion did not slay, the wolf was not carrying off lambs, the dog had not been taught to make kids curl up, the pig had not learned that grain was to be eaten.

When a widow spread malt on the roof, the birds did not yet eat that malt up there. The pigeon then did not tuck the head under its wing.

No eye diseases said there: 'I am the eye disease (igi-gig).' No headache said there: 'I am the headache (saĝ-gig).' No old woman belonging to it said there: 'I am an old woman.' No old man belonging to it said there: 'I am an old man.' . . . No herald made the rounds in his border district.

No singer sang an elulam there. No wailings were wailed in the city's outskirts there. ${ }^{23}$ 
While the myth does not relate how the different diseases came into being, it nonetheless refers to a primordial paradisiacal time, when neither violence, sickness, old age nor death were known. But interestingly, the text then tells how the god of wisdom Enki became ill through his own action, when he ate a number of plants cultivated by the goddess Ninhursag. When Ninhursag curses Enki for having eaten her plants and for having 'determined their destinies' (Sumerian nam-tar, line 219), Enki becomes sick and can only be cured by Ninhursaĝ, who removes the sickness from Enki's aching body parts, thereby 'giving birth' (tud) to a number of deities.

In other Babylonian texts such as the Atramhasīs myth, the gods intentionally install certain health hazards and bodily impairments: the baby-snatching demoness responsible for infant mortality and the infertile woman ('the woman who does not bear'), in order to put an end to humanity's uncontrolled reproduction rate, after they had rather unsuccessfully tried to cut down and wipe out mankind by bringing famine, an epidemic and a flood. ${ }^{24}$ Again, it is noteworthy that at first, when mankind had been created and installed by the gods as their servants and workers, they were apparently not yet affected by sickness and thrived in an uninhibited manner. But in Atramhasīs, sickness, just as life, creation and death, is brought into existence by the collective decree of the gods. ${ }^{25}$

In incantations used for healing, we also encounter the mythological model of disease as initiated by divine action, e.g. in an Old Babylonian spell against indigestion (stomach ache or 'sick/bound belly'), in which the sun-god Šamaš picks up a plant (šaman libbi 'Belly Plant') on a mountain, thereby causing the plant to 'seize' his belly as well as the belly of various animals and humans: ${ }^{26}$

The Belly Plant [was growing] on [the mountain, and Šamaš picked it up].

[It seized the belly of] Šamaš [who picked it up].

[It sei]zed the herds[man] Sîn (i.e. the moon god),

[It sei]zed the belly of the ox in the fold,

It seized the belly of the sheep in the p[en],

It seized the belly of So-and-So, son of So-and-So, whose god is So-andSo, whose goddess is So-and-So . . ${ }^{27}$

An alternative mythological origin of diseases is encountered in connection with sickness-bringing demons. These beings are said to have come into existence in primordial times before the instatement of a divinely ordered cosmos. They are either said to have come out (or sprouted) from the earth (like plants) or they are the children of the primordial divine couple Heaven and Earth $(\mathrm{An} / \mathrm{Ki})$, related both to the netherworld and the celestial domain. ${ }^{28}$ Similar 'genealogies' in the form of a chain are also found in incantations against certain disease agents, such as the 'tooth worm' $(t \bar{u} l t u)$ held responsible for tooth decay:

After Anu created heaven, heaven created the earth. Earth created the rivers, 
The rivers created the canals,

The canals created the mud,

The mud created the worm . . . 29

In the spell, the worm complains to the gods Šamaš and Ea that he has only figs and apples to suck on and that he would prefer to dwell between teeth and jaw and suck the blood from the jaw. While the worm is cursed for his demand in the incantation ('May Ea strike you with the might of his hand!'), the gods apparently did not hinder the worm from taking up his habitat in peoples' mouths in the first place, but they intervene on behalf of humankind through their knowledge of magic and medicine to relieve the problem. Thus, Mesopotamian mythological accounts seem to imply that once sickness and agents of disease have become part of the world whether they were present since time immemorial or were brought into being by the gods - they can only be held at bay by divine intervention and driven off to their domain far away from human settlements; they can never be destroyed completely.

\section{Personalising and impersonal aetiologies}

Mesopotamian medicine employs two basic types of aetiologies, which can be compared with the comparative typologies proposed in anthropological literature that formulate a contrast between 'personalistic' and 'naturalistic' aetiological models, or differentiate between medical cultures that emphasise personalising aetiologies and those emphasising impersonal forces as responsible for pathological processes. ${ }^{30}$ In Assyriological studies, the contrasting terms 'natural' and 'supernatural' causes are often used, but designations such as 'natural', 'naturalistic' or 'supernatural' are partially problematic, because Mesopotamian culture and science do not operate with a concept of 'nature' comparable to the Western concept, which is based on and goes back to Greek philosophy (Rochberg 2016b). In Mesopotamian culture, super-human beings such as demons or gods, although differentiated from other categories of beings, were rather perceived as much a part of the real world and natural environment as animals or plants. Instead of the misleading terms 'natural' and 'supernatural', the alternative terms 'personalising' and 'impersonal' could be suggested to differentiate the basic aetiologies which cuneiform medical texts employ to conceptualise and explain different diseases, accentuated further by the intersecting differentiation between external and internal causes (Steinert 2016: 215-19). ${ }^{31}$ These terms are better suited to grasp Mesopotamian concepts than the categories 'personalistic' and 'naturalistic', since it can be shown that these two aetiologies are not mutually exclusive but often occur within Mesopotamian texts in a combined or overlapping fashion.

\section{Personalising aetiologies in Mesopotamian medicine}

Personalising aetiologies attribute sickness to the active intervention or attack of a sensate agent (human or non-human), and the sick person is the object of 
aggression or punishment. This kind of aetiology is amply attested in Mesopotamia and has often been emphasised in research. ${ }^{32}$ We encounter personalising aetiologies in recurring expressions that the patient is 'hit/struck' or 'seized' or afflicted by a disease (agent) and in specific diagnoses such as the 'Hand of god X/goddess Y', 'Hand of a ghost', 'Hand of demon/spirit Z', 'Hand of a (broken) oath' (mamītu) or 'Hand of mankind' (for the latter there is also a synonymous term, kišp $\bar{u}$ 'sorcery'). These diagnoses are aetiological labels referring to more or less diverse and varying sets of (physical, psychological or mental) symptoms, which can occur separately or together and which could be called 'syndromes'. ${ }^{33}$ That is to say, these aetiological terms 'stood, through complex symbolic or metaphorical associations, for actual disease patterns, clustered in functional classes' (Fales 2016: 19; cf. next). It is important to note that personalising aetiologies are predominantly encountered in the diagnostic texts (e.g. in the Diagnostic Handbook), which belonged to the text corpus of the āšipu 'conjurer/ritual expert': 34

\section{Diagnostic Handbook Tablet 22: 2-3 (Heeßel 2000: 250-1, 258; cf. Scur- lock 2014: 185, 188)}

If paralysis continually falls upon him, his epigastrium continually afflicts (literally 'seizes') him, and he is very constipated, then his illness is due to the 'Hand of mankind'. Figurines of him have been made to lie (with a corpse); the $\bar{a}$ šipu should not make a prognosis ( $q \bar{\imath} b u)$ concerning his recovery.

\section{Diagnostic Handbook Tablet 22: 14-15 (Heeßel 2000: 252, 259; cf. Scur- lock 2014: 186, 189)}

If a man's penis or epigastrium hold burning fever, the 'pouch of his belly' (takalti libbi) hurts him and his belly raves, (and) his arms, his feet and his belly are hot, this man is sick with a disease of sexual intercourse; (it is due to the) 'Hand of the goddess Ištar'. ${ }^{35}$

\section{Diagnostic Handbook Tablet 22: 40 (Heeßel 2000: 255, 260; cf. Scurlock 2014: 187, 190)}

If he suffers from convulsions and continually asks (variant: does not ask) for water or 'beer', then the lurker-demon of the road has struck him.

Personalising aetiologies are also encountered, though less prominent in the therapeutic corpus (i.e. in medical recipes), which we attribute primarily to the corpus of the $a s \hat{u}$ 'physician':

\section{BAM 503 i 30' (Scurlock 2014: 370, 380)}

If due to affliction (lit. seizure) by the 'Hand of a ghost', a man's ears roar, you fumigate the inside of his ears with root of e'ru-tree, nikiptu-plant and 'soiled rag' over coals. 


\section{K 3628+ rev. 20-21 (Scurlock 2014: 624-6)}

[Exc]erpt of treatments for an infant whom 'Fallen-from-heaven'-disease, 'Lord of the roof', ['Hand of the god', 'Hand of] Ištar', lilu-demon or evil al $\hat{u}$-demon afflicts (lit. seizes).

Personalising aetiologies and disease agents prominently encountered in therapeutic texts are the 'oath/curse' (mamitu), the 'Hand of the (personal) god/ goddess' and forms of evil sorcery. ${ }^{36}$ While some symptoms or symptom combinations are typically attributed to a specific agent and a logic linking symptoms and agent is occasionally discernible, the motivation for the correlation escapes us in many cases. Some deities and demons 'specialise' in particular conditions falling into their functional realm: for instance, the goddess of sexuality Ištar is connected with 'diseases of intercourse' (muruṣ nâki), while the demoness Lamaštu attacks mainly babies and pregnant women and is associated with fevers or miscarriage. ${ }^{37}$

As a rule of thumb, one could formulate a tendency that the more complex and prolonged, serious or life-threatening a disease, the more often an attribution to a personalised agent is established in the texts, although this does not hold true in all instances (less serious complaints can also be caused by a deity, e.g. by the personal god). Demons can be associated with places in the environment which represent their habitat (e.g. the lavatory, desert, rivers). They are predominantly described as attacking the human victim, either because they are 'evil' (i.e. hostile), or because the victim happened to be in their reach, but they can also act as divine deputies ( $\check{s} a n \hat{u} / \check{s} \bar{e} d u)$, sent by a specific deity with the instruction to bring sickness upon a human being who caused the deity's wrath. ${ }^{38}$ Sicknesses caused by gods are predominantly linked to moral transgressions, wrongdoing, the breaking of specific taboos or religious neglect of the patient, which provoke the divine wrath. But as the hemerological literature as well as other texts inform us, a deity could easily become angry, for instance if one ate the wrong thing or went out to a garden on the wrong day (Livingstone 2013: 263-6).

\section{Impersonal aetiologies in Mesopotamian medicine}

In some Mesopotamian texts, sickness is explained or described in rather impersonal terms. Here, health problems are typically regarded as due to impersonal ('natural') forces, influences or conditions in the environment (e.g. heat, cold, winds, dampness), and disease is conceptualised as an irregular or abnormal process in the body. The notion of irregularity can be compared with the concept of illness as an imbalance (of the elements in the body, or between the body and the natural environment), an idea which is prominent in the humoral theories known from Chinese and Greek medicine. ${ }^{39}$ Although a comparable sophisticated humoral theory based on the idea of (im)balance was never developed in Mesopotamian medicine, we encounter a number of impersonal aetiologies, some of which allude to similar concepts about the body and its relationships with the environment. ${ }^{40}$ 
A common idea encountered in Mesopotamian medical texts is that parts of the body can malfunction by themselves (for no particular reason) and cause symptoms:

\section{BAM 87 obv. 1-5 (cf. Scurlock and Andersen 2005: text 6.129)}

If a man's takaltu-organ (lit. 'bag') seizes him, so that he suffers from a stinging pain in the belly, his belly hurts him, his inside is 'far' to him, . . ., his whole body is 'poured out', he has bloating of the belly, he suffers from 'pouring out' of arms and feet: (then) this man suffers from a disease of the takaltu-organ. To cure him: ... (recipe follows).

\section{AMT 40/5 iii 9 (Geller 2005: No. 23 Ms. X)}

If a man's intestines are continually bloated, he has (only) little appetite for bread and beer (and) he is always constipated, this man [suffers from] constriction [of the anus].

At the beginning of the first of the two cited passages, an organ called takaltu 'bag' (possibly here referring to the stomach) is verbally constructed as an active agent 'seizing' the patient and thus causing a number of symptoms experienced by the patient. This phrasing is otherwise typical for describing sickness as an attack of a personalised being (e.g. a demon or deity), thus implying the attribution of agency to an internal organ and an overlap between personalising and impersonal aetiologies. ${ }^{41}$ However, the diagnosis identifies the patient's disorder as a 'disease of the takaltu-organ'. This expression corresponds to general technical labels referring to localised conditions such as 'sick eyes', 'sick belly', which are regular encountered as part of text rubrics or diagnostic statements. ${ }^{42}$ In a similar way, the second passage describes the symptoms and stipulates a diagnosis through a descriptive disease name ('constriction of the anus').

It is also worth pointing out certain similarities with Greek or Tibetan humoral pathologies attributed to an excess of a humour such as phlegm or bile. Thus, Mesopotamian texts recognise comparable conditions, which are caused by bodily fluids or by 'wind' in the body:

\section{BAM 578 ii 20-21 (Scurlock 2014: 511, 522)}

If, before having eaten, a man's epigastrium gnaws at him, he continuously has internal fever (and) when he belches, he vomits bile: that man is sick with pāšittu (gall fluid) or tugānu-disease. To cure him: . . . ${ }^{43}$

\section{BAM 159 v 48-50 (Scurlock 2014: 499-501; Parys 2014: 23, 35 § 69)}

If a man's intestines are continually bloated, his bowels rumble, his bowels continually make a loud noise, 'wind' groans in his belly and 'buts' into his anus, that man is sick with pent-up (wind). To cure him: . . . 
We also encounter the idea that external impersonal forces and entities such as climate, weather, sun light/heat, wind and the seasons exert an influence on the body and can cause sickness. ${ }^{44}$ Most prominently, wind blowing against or entering the body is held responsible for a number of conditions. Noteworthy is also seetu 'sun-heat', which refers to the heat and light emitted by the sun as well as to an internal ailment linked primarily with fever and digestive disorders: ${ }^{45}$

\section{BAM 145: 1-17 // BAM 146: 29-38' (Scurlock 2014: 422-4; Bácskay 2018: 181-6)}

If a man is burned by 'sun-heat', so that the hair of his head continually stands on end, his face continually seems to spin, he constantly feels burning hot, his body is always tired, (but his) temperature is (only) lukewarm, he constantly suffers from cough, his belly is constantly upset, his saliva flows, his belly turns over and over, he is sick from flowing of the bowels (diarrhoea), ..., his flesh (body) above is cold, but his bones below (feel) burning hot, ... (and) he continually feels the burning of intestinal fever: that man is burned by 'sun-heat'. ${ }^{46}$

\section{BAM 159 iv 11' - 12' (Scurlock 2014: 365-6; Parys 2014: 20, 33 § 49)}

If a man's eyes have been blown by the wind so that they are clouded, confused and continually shed tears, ... (recipe follows).

Although in some text passages, 'wind' is described as an impersonal entity causing complaints inside or on the outside of the body, in other contexts such as incantations, the wind can be addressed like a sensate agent and urged to leave the body. Winds are moreover closely associated with demons or ghosts, which share a wind-like existence enabling them to enter the body of their victims through body openings: ${ }^{47}$

\section{Diagnostic Handbook Tablet 22: 49-50 (Scurlock 2014: 187, 191)}

If his [mind] is continually altered, his words are unintelligible and he forgets whatever he says, (then) a wind from behind afflicts him.

A comparable overlap between the idea of sickness as an impersonal process and an underlying personalised agent can be found in connection with the ingestion of spoiled food or dirty water, which are often described as poisoned or 'bewitched' by evil sorcery: ${ }^{48}$

\section{Diagnostic Handbook Tablet 13: 32 (Scurlock 2014: 104, 111)}

If his epigastrium holds fever (and) his mind is continually altered, he drank water from a hoisting device of the river. ${ }^{49}$ 


\section{BAM 237 iv 29-30 (Scurlock 2014: 577, 581)}

If a woman has been given 'plants/drugs of hatred' to eat (and because of this) fluids flow excessively from her vagina, ... so that her illness will not be prolonged: ... (recipe follows)

\section{BAM 90: 3'-6' and parallel AMT 48/2 obv. ii 11-14 (Abusch and Schwe- mer 2011: 239, 243)}

[If a man eats bread? and after]wards he drinks beer, but he is not at ease in his belly, [his belly] heaves constantly, he takes repeated baths in water, but he is constantly irritated [and he keeps itching?], - this man [is bewitched and] has been given dirty substances to eat with bread or to drink with beer (var. he has been given dirty substances to drink with water). To cure him: . . .

Impersonal aetiologies also underlie diagnoses or disease names referring to specific places in the environment, implying the idea that one can contract diseases at certain places (such as the steppe or the mountains, which are often associated with demons, spirits or other hazards as well) or that specific diseases have a place of origin. ${ }^{50}$ Moreover, in the therapeutic incantations (used by both conjurers and physicians), pathological processes based on malfunctioning body parts are very often described in terms of analogies and metaphors drawing on the perception and experience of parallel processes in the body and the environment ${ }^{51} \mathrm{In}$ Mesopotamian medicine, such analogies do not predominantly reflect the notion of a 'body-ecologic' (Hsu 2007), based on the idea of a dynamic equilibrium of bodily substances or energies which are linked to homologous cosmic forces and seasonal processes in the environment. The Mesopotamian conception reflects more a 'body-technologic', because here we find the central idea of therapy as regulation of irregular body processes, expressed through metaphors stemming predominantly from technologies such as agriculture (water management and irrigation) or from cooking, brewing and pottery (Steinert 2017a). In healing spells, the body is described as a container filled with fluids, with orifices connected by canals, in which transformative and dynamic processes take place, especially in connection with gastrointestinal or other internal ailments: ${ }^{52}$

\section{CT 4, 8a: 1-21 (Foster 1996: no. II.19; SEAL text 5.1.4.1; Steinert and Vacín 2018)}

The sick belly is closed up like a basket,

like the waters of a river it does not know where it should go, it has no flow like water of a well, its orifice is covered like (that of) a fermenting vat, no food and drink can enter it. Asalluhi-Marduk has looked into it, and he calls out to his father Enki-Ea:

'My father, the sick belly is closed up like a basket, 
like the waters of a river it does not know where it should go, it has no flow like water of a well, its orifice is covered like (that of) a fermenting vat, no food and drink can enter it.' Enki-Ea answers Asalluhi-Marduk:

'My son, what do you not know and what could I add for you?

Whatever I know, you know too, whatever you know, I know as well.

Be it a human, be it cattle, be it sheep:

When he has added? a lump of salt and thyme ..., May it burst on the ground like dung.

May it burst out like a burp.

Come out like wind from the anus!'

Incantation for the belly.

This bilingual Old Babylonian spell illustrates the typical environmental and technological body metaphors and is an example for the 'classical' compositional structure popular in Sumerian as well as Akkadian healing spells, featuring the so-called Marduk-Ea dialogue. In other incantations, the bodily processes are described merely through allusion to environmental processes, as in the following spell recited in connection with draining fluids (or an abscess) from the skull, included in a tablet belonging to the treatise on conditions of the head (CRANIUM). The text addresses the disease urbatu, elsewhere referring to (an infestation by) intestinal worms, depicting it as an elusive entity that materialises in the form of a red cloud raining down, producing a rising river flood that needs to be released by proper canalisation work: ${ }^{53}$

BAM 480 iii 65-68 (Collins 1999: 277-8; Foster 2005: 992; Scurlock 2014: 441-3)

'Urbatu, urbatu!' The red urbatu rose up and covered the red cloud.

The red rain rose up and poured down on the red earth.

The red flood rose up and filled the red river.

Let the red farmer take up the red 'spade' and the red hod and let him dam up the red water!

The door is red, the bolt is red. Who is the one who will open their locked door for you (water)? ...

Recitation so that [the waters of the head] are not held back (to ensure the drainage of an abscess).

This spell is recited during the preparation of an amulet of wool and cloth worn by the patient around his temples; it was probably applied after the surgical draining of an abscess on the head described in a passage preceding the incantation. The focus on the colour red and the imagery is clearly intended as a link to the bloody fluids released from the patient's skull. A third example illustrates a healing spell against fever ('fire') preserved in first millennium BCE incantation collections, 
in which the sickness is addressed as a personalised agent and conjured to leave the patient's body:

\section{Lambert 1970: 40 lines 5-15; after Foster 2005: 972}

'Incantation': Fire, fire!

Fire of the storm, fire of the battle, Fire of death, fire of pestilence, consuming fire!

Your smoke cannot be smelled, your fire does not warm.

May Asalluhi drive you away and send you across the Tigris river!

I conjure you by the god Anu, your father,

I conjure you by goddess Antu, your mother -

Go out, like a snake from your (hole in the) foundation,

Like a partridge(?) from your hiding place!

Do not go back to your prey!

Disperse like mist, rise like the dew,

Go up like smoke to the heaven of Anu!

These examples of healing spells reveal certain recurring images and a repertory of narrative patterns, which served to depict and transform the illness experiences into a recognisable entity or being that could be acted against. We can discern two major strategies of dealing with or bringing under control the disorder and its adverse effects. In the first spell, the disorder ('sick belly') is depicted through 'natural', daily life processes - a box or basket that is closed, a well that has no flow - processes which are in themselves normal, but contrary to the condition of a healthy belly and to the normal digestive processes, described as a river or canal in which fluids enter at the top opening, are transported downstream and released through the bottom exit. Often in such spells, the problem is observed or brought to the attention of the healing gods, who intervene on behalf of the patient to bring the bodily processes back to normal. These interventions are either described in the form of instructions for a remedy (as in the Marduk-Ea dialogue of CT 4, 8a) or through metaphors as in the second spell against urbatu, in which the disorder is pictured as a weather phenomenon affecting the environment (the agricultural landscape) and in which the curative actions are likened to the manual interventions of a farmer opening the sluices of canals to disperse a huge river flood. The third spell against fever reflects the personalised understanding of disease as an agent whose actions are invasive or damaging to the body or the environment. ${ }^{54}$ While metaphors are likewise encountered, here the personalisation and direct address of the disorder enables the speaker to dispel and manipulate the aggressor. However, many Mesopotamian therapeutic incantations combine elements and imagery, playing with both the personalising and impersonal aetiologies. And as will be shown next, the diagnostic and therapeutic medical texts often present a layered understanding of disease in terms of a complex relationship between bodily processes or signs and environmental causes that are conceptualised to varying degrees as personalised agents or as impersonal forces. 


\section{Systematic classification in Mesopotamian medicine?}

The discussion of aetiologies has already illustrated the multifaceted and complex understanding of sickness and diseases in Mesopotamia. ${ }^{55}$ The following pages aim at describing patterns of classifying different complaints and disorders encountered in Mesopotamian medical texts. These classificatory endeavours reflect attempts of ancient healers and physicians to make sense of sickness episodes that they observed, reflecting an engagement with lived experience, combining both bodily and sensory perceptions (of healer and patient), observations as well as intellectual processes drawing on empirical knowledge, imagination and analogy. The goal of the discussion is to point out culture-specific aspects of Mesopotamian disease classification and nosology as well as cross-culturally encountered principles of classification connected to common bodily experiences and perceptions.

A second point to be scrutinised is the question to which extent Mesopotamian medical texts and their classifications of different disorders reflect a 'system'. Thus, anthropological research on African medical cultures shows that medical knowledge can frequently be dynamic, incoherent and contradictory (Littlewood 2007), and that popular as well as traditional specialists' disease concepts often do not constitute a consistent body of theory or form vast systems of classification with a fixed, uniform or stable structure. Can we discern comparable inconsistencies in Mesopotamian medical texts, or are there noticeable developments pointing to a systematisation of knowledge concerning different types of pathologies and to a sophistication of medical concepts? In what follows, I will outline different patterns of naming diseases in medical cuneiform texts. Then I will discuss textual patterns that serve to present pathological and nosological entities as representatives of a semantic domain or as a class of similar conditions, ranging from lists of disease names to the topical organisation of medical handbooks and compendia. I will argue that the medical texts of the first millennium BCE show several tendencies towards a systematisation of medical knowledge concerning the range of conditions Mesopotamian healers treated, and towards more sophisticated concepts of physiology and nosology based on different correspondences between the human body and the natural/ social environment.

\section{Disease names and 'families' of related conditions}

Looking at both Sumerian and Akkadian designations found as diagnoses (but also encountered as logograms in thematic text rubrics), one can differentiate at least three broad types of names: (1) names with body part terms; (2) descriptive or metaphorical terms or expressions; and (3) names involving a causative agent (aetiological designations). The different designations vary with regard to their scope and precision: disease names can range from generic terms that more or less cover a class or group of related conditions, to more circumscribed disorders 
and entities. Moreover, some terms occur both as a disorder with the value of a diagnosis as well as a symptom (e.g. bleeding, diarrhoea or bloating).

Names formed with body part terms refer to pathological conditions located in an anatomically circumscribed area of the body, illustrated by the Sumerian expressions SAG.GIG 'sick head/head ailment', IGI.GIG 'sick eye', ZÚ.GIG 'sick tooth', MUR.GIG 'sick lung', Š̀̀.GIG 'sick belly/inside', DÚR.GIG 'sick anus' (or rectal disease), or their Akkadian counterparts murus qaqqadi 'disease of the head', muruṣ pî u šinni 'disease of the mouth and tooth', muruṣ hašê 'disease of the lungs' etc. Often these designations are used as generic terms, e.g. in enumerations of diseases in incantations or within rubrics specifying types of incantations, but some of them are also encountered in the diagnostic entries of medical texts, in introductory phrases or in the diagnosis itself. In most cases, expressions of the type 'disease of body part $\mathrm{X}$ ' are not used to refer to specific disorders in a strict sense, although one can say that they serve as technical categories referring rather to anatomical classes of conditions, some of which are associated with sets of pathological symptoms, as in the case of DÚR.GIG 'sick anus' (or rectal disease). ${ }^{56}$ The following passages illustrate the occurrence of DÚR.GIG in the introductory formula opening a symptom description as well as in the concluding diagnosis, pointing out different key symptoms, such as pain in the groin and extremities, constipation and haemorrhage from anus or urethra:

If a man suffers from rectal disease (DÚR.GIG, lit. 'sick anus') and his anus continually stings him ...

(AMT 56/1 obv. 10 and BAM 88: 10’; Geller 2005: No. 27: 10’)

If a man has rectal disease and his anus is blocked up ...

(BAM 95: 21 and duplicate; Geller 2005: No. 21:21)

If a man suffers from rectal disease and defecates blood, ...

(BAM 95: 27 and duplicate; Geller 2005: 21:27)

If a man's limbs are continually 'poured out', his chest and back continually hurt him, his arms, sh[ins and knees] continually hurt him, his loins either on the right or left side give him a jabbing pain, and from his urethra he shows blood, that man suffers from the constriction of rectal disease. To cure him: ...'

(AMT 40/4 iii 14' - 16'; AMT 56/1 obv. 1-3; BAM 88: 1'-2'; Geller 2005: No. 23: 14' - 16')

Among the disease names formed with body part terms, we often encounter metaphoric or descriptive expressions, such as Š̀̀.SI.SÁ 'straight inside' and ridût irri 'overflowing of the bowels' (diarrhoea), hīp libbi 'heartbreak', kīs libbi 'bond of the belly' (constipation/indigestion), SAG.KI.DAB.BA 'seizing of the temple' 
(headache/migraine). These expressions usually stand for circumscribed conditions characterised by a central symptom, but they can feature both as a symptom of a disorder and as a diagnosed condition in themselves:

\section{BAM 317 rev. 24-26 (Abusch and Schwemer 2011: text 1.5)}

If a man's face seems to 'spin' constantly, his limbs are 'poured out' all the time, he constantly feels oppression (and) 'heartbreak' (and) fear, then the 'Hand of mankind' is upon him.

\section{BAM 316 iii 13-14 and dupl. (Buisson 2016: 36)}

If a man constantly has 'heartbreak' and is terrified day and night, then his god is angry with him. To pacify his god with him: ...

\section{BAM 316 ii 5'-9' and dupl. (Abusch and Schwemer 2016: text 3.6)}

If a man is constantly frightened, he worries day and night, he is repeatedly suffering losses, his profit is cut off, (people) slander him, who(ever) speaks to him does not speak the truth, an (accusing) finger of evil is pointed at him, in his (lord's) palace his presence is no longer welcome, his dreams are terrifying, he keeps seeing dead people in his dream(s), (then) 'heartbreak' is afflicting him.

Among the metaphorical terms, some can refer to conditions caused by sorcery (e.g. ZI.KU 5. RU.DA 'Cutting of the throat' or KA.DAB.BÉ.DA 'Seizing of the mouth'), which allude to specific magical techniques causing certain typical symptoms and problems. ${ }^{57}$

The third type of disease names, designations identifying a causative agent, mostly take the form 'Hand of NN' (e.g. 'Hand of the god', 'Hand of a ghost', 'Hand of mankind'; 'seizure/touch of NN'), but there are also designations referring e.g. to a specific demon, type of sorcery or other super-human entity (such as 'Lord of the roof' or the 'curse/oath'). Disease names involving super-human agents can refer to multiple, quite different conditions (in biomedical terms). Thus, a deity or a ghost could be held responsible for causing various combinations of symptoms and ailments (or 'syndromes'), and vice versa, very similar symptoms may be attributed to different agents. The identification of an agent thus depended on specific combinations of symptoms.

A considerably large group of Akkadian terms refers to more circumscribed and specific disorders or pathological entities. In the medical texts, many of these conditions are identified and described by a set of distinct symptoms. Many of the names that have a transparent etymology (which is not always the case) express a typical feature or characteristic of the condition in question, and thus can be counted among the descriptive type of disease names. A few of these terms, such as amurriqānu 'jaundice', occur both as a disorder and as a symptom of other disorders. In the following, I offer a selection of such 
terms and characteristic diagnostic entries, drawing mostly on Tablet 33 of the Diagnostic Handbook, which deals mainly with different kinds of skin conditions characterised by sores or lesions (simmu). A noteworthy sign for the status of these terms as distinct nosological entities is the diagnostic formulation 'so-and-so is its name', a formula found also in some therapeutic texts (cf. Stol 1991-92: 64):

sāmānu 'the red one':

If the appearance $(\check{s i k n u})^{58}$ of the sore is that it is red, hot, swollen and flows, [it is called] sāmānu (literally 'sāmānu is its name').

If the appearance of the sore is that it is red, and the patient continually gets feverish and continually vomits, [it is called] sāmānu. ${ }^{59}$

šadânu lit. '(hard) like a $\operatorname{rock}(?)$ ':

If the appearance of his sore is that it is (hard) like obsidian (and goes) around his neck, it is called šadânu. . . .

If the appearance of his sore is that it is hard to the touch, he is burning hot, his 'pouch' (stomach?) is swollen and his appetite for bread and beer is diminished, (then) it is called šadânu; (it is due to) the touch of the 'Hand of $[\ldots] '{ }^{60}$

girgiššu 'strawberry':

If the appearance of his sore is that it is hot like a burn, [. . .] does not contain fluid $[\ldots] \ldots$, it is called girgǐ̌s $u .{ }^{61}$

sikkatu 'peg-(shaped) lesion'62

ekkētu 'scratching':

If the appearance of the sore is that it is like an ummedu-lesion (and) it goes around his hips, it is called ekketu. ${ }^{63}$

$a \check{s} \hat{u}:$

If the appearance of the sore is like an ummedu-lesion, it itches him and (when) he scratches, the surface of the sore produces a fluid, [...], it is called ašû. . . .

If his face is swollen, his eyesight diminished, his body is full of birdunodules and his abdomen afflicts him, it is called $a \check{s} \breve{u} .^{64}$

išātu 'fire' 65

The passages extracted from Tablet 33 lines 1-86 of the Diagnostic Handbook show that the various conditions were characterised and differentiated through distinct observable features or symptoms. In some instances, the text offers 
multiple 'clinical' descriptions of the same ailment in a group of lines, which present some overlap and variation in the described symptoms. These variant descriptions of the same nosological entity may sometimes reflect different underlying 'cases' (stemming from the observation of multiple patients or illness episodes) or manifestations of a condition with varying degrees of severity. However, some of the ailments in Tablet 33 are found in such a range of varying contexts (e.g. when a term occurs as a disease of humans, animals and plants) or is linked with disparate symptoms that it seems more than likely that each of the terms covers several different diseases (in biomedical terms), reflecting decisive divergences and incompatibilities between Mesopotamian nosological entities and biomedical diseases. However, one also has to reckon with diachronic changes in the usage and meaning of the Akkadian terms and with local variations in medical terminology.

The representations behind Mesopotamian disease names such as the different skin conditions in Tablet 33 of the Diagnostic Handbook have much in common with the illness 'modules' described by Olivier de Sardan $(1998,1999)$ in his study of West African medical systems. The 'illness modules' are of variable scope and complexity; some of them can form families with partially overlapping symptoms which are loosely organised into an 'ensemble'. But they are not organised into a hierarchically ordered classificatory system. In a similar vein, Tablet 33: 1-86 groups ailments that are loosely characterised by skin 'sores', which suggests that they form a 'family' of conditions, each of which is differentiated on the basis of external appearance of the sore and other associated symptoms, which can vary. Occasionally sub-types of the same condition are differentiated in the texts, but apart from their loose association, the passage in Tablet 33 does not appear to reflect an apparent system underlying the classification of skin sores. ${ }^{66}$

Another ruled-off section in Tablet 33: 87-102 follows the same diagnostic formula as the preceding passages ('it is called NN'), but presents a different group of ailments. Here, the common denominator of the conditions is not so easily apparent, since the entries include infectious conditions and ailments of the extremities, muscles and sinews. Possibly, the passage covers a number of common ailments, since they are also treated in therapeutic texts, albeit in different compendia contexts (cf. the following). Among them are the following diseases dealt with in therapeutic treatises on ailments of the mouth/throat and on gastrointestinal conditions:

bu'šānu 'stench; stinking':

If his mouth is full of bubu'tu (blister-like lesions) and his saliva flows, it is called bu'šānu. ${ }^{67}$

If $b u$ 'šannu has seized a man's [nose/mouth] so that his nostrils hurt him and are full of sores ... if something smells in his nostrils ...

amurriqānu 'jaundice': 
[If his body is yellow, his face is] yellow and his eyes are yellow and he has wasting away of the flesh, it is called amurriqānu. ${ }^{68}$

ahhāzu 'the gripper':

[If his face is] 'yellow' and the inner part of his eyes is yellow (but) the base of his tongue is black, [it is called] ' $a h h \bar{a} z u^{\urcorner} \cdot{ }^{69}$

The last two entries, which are found in immediate sequence in Tablet 33, illustrate a kind of differential diagnosis, giving specific symptoms which allowed the healer to differentiate between two similar conditions: amurriqānu 'jaundice' (a word derived from the verbal root meaning 'to be yellow-green') and ahhāzu, literally 'the gripper', referring both to a demon and a condition characterised by a type of intermittent fever and jaundice. ${ }^{70}$ In the cited two lines, amurriqānu is recognised by the symptom of 'wasting away of the flesh' (emaciation), while ahhāzu shares with amurriqānu the yellowing of the eyes and face, but is differentiated from it by the darkening of the 'base of the tongue'. ${ }^{71}$ The ancient healers used fine-tuned differences in the manifestation of symptoms to differentiate between other febrile conditions related to $a h h \bar{a} z u$, noting for instance the duration of the fever attacks or bouts of sweating as crucial symptoms (cf. also the following):

\section{Diagnostic Handbook Tablet 16: 12 (Scurlock 2014: 152, 156)}

If over the course of one day it leaves him but then (later febrile seizures) come over him for one day, (it is) 'eating of $A h h \bar{a} z u$ ' (or/due to the) 'Hand of the great gods'; he will die.

\section{Diagnostic Handbook Tablet 19/20: 113'b (Scurlock 2014: 179, 182)}

If it (the fever) afflicts him daily as in 'seizure of Lamaštu', (then it is) 'Hand of Labāṣu'.

\section{CTN 4, 72 vi 14'-16' (Stadhouders 2011: 45-8)}

If (during his illness) he continually has much sweat (as in) Labāṣu and (in addition) chills keep falling on him: 'Hand of a fierce (i.e. persistent) deity', (or) deputy spirit of Ea.

Another 'family' or 'ensemble' of closely related conditions are those characterised by seizures or epileptic fits. Therapeutic texts as well as diagnostic texts and commentaries show that Mesopotamian healers differentiated several kinds of epileptic fits or seizures which are associated with a limited group of super-human agents and which are often found together in disease lists or in therapeutic contexts: AN.TA.ŠUB.BA, literally 'what has fallen from heaven', the demon 'Lord 
of the roof', 'Hand of the god', 'Hand of the goddess' and 'Hand of a ghost'. ${ }^{72}$ The connection between these conditions is illustrated in Tablet 28 of the Diagnostic Handbook, the first lines of which deal with cases of different types of epilepsy 'turning' or changing into one another:

If 'Hand of a ghost' turns into AN.TA.ŠUB.BA for him: that man is ill due to the 'Hand of his city god'....

If 'Hand of the goddess' turns into AN.TA.ŠUB.BA for him: (it is due to) 'Hand of Sîn', (or) 'Hand of Ištar'. . . .

If 'Hand of the goddess' turns into 'Lord of the roof' for him: 'Hand of Šamaš'.... .

If 'Lord of the roof' turns into AN.TA.ŠUB.BA (or) into 'Hand of the goddess' for him: 'Hand of Ištar'... . ${ }^{73}$

A Late Babylonian commentary to a therapeutic text with fumigations for various ailments explains the characteristic symptoms of each of these related conditions, which allowed the healer to differentiate between them: ${ }^{74}$

AN.TA.ŠUB.BA - (when) the patient is constantly choked and lets his spittle flow, it is AN.TA.ŠSUB.BA. ${ }^{75}$

'Lord of the roof' - (when) he turns away his right eye and his left eye, it is 'Lord of the roof'. ${ }^{76}$

'Hand of the god' - (when) he curses the gods, speaks insolence and hits whatever he sees, it is 'Hand of the god'. ${ }^{77}$

'Hand of the goddess' - (when) he continually gets oppression (and) 'heartbreak' and continually forgets his words, it is 'Hand of the goddess'. ${ }^{78}$

'Hand of a ghost' - (when) his ears roar, he . . . very much, he cannot bring his teeth close to food, it is 'Hand of a ghost'. ${ }^{79}$

A recurring presentation of Mesopotamian disease names that can likewise be compared with the 'ensembles' or families of ailments described by Olivier de Sardan $(1998,1999)$ is the form of lists (or enumerations). Disease lists belong to the genre of the lexical texts studied by scribal students, but they also served as models for lists of ailments embedded in incantations or other literary texts. ${ }^{80}$ The lexical lists of disease terms are comparable for instance with thematic lists of body parts and anatomical terms, but while the latter are primarily organised 'from head to foot', the disease lists differ from the former since they lack a consistent, homogenous principle of ordering or organisation of the terms in definite classes. Occasionally however, one can discern groupings of terms within the lists (either based on a thematic or a graphic principle, e.g. groups of skin ailments, or groups of lexical entries starting with the same cuneiform sign). ${ }^{81}$

Enumerations (or catalogues) of diseases and demons, likewise without an obvious or consistent organising principle (anatomical or thematic), were also integrated into Old Babylonian and later incantations. ${ }^{82}$ These lists are never 
identical and feature varying terms, although it is possible to draw up a 'minimal sequence' (or 'skeleton list') of representative diseases that typically figure in the enumerations (Wasserman 2007: Table 1 and 2). At least among Old Babylonian incantations, one finds two groups of compositions with lists of disease names, namely spells that include names of demons and spells that do not include demons but rather attribute the origin of the listed diseases to environmental influences. ${ }^{83}$ Comparable lists in later texts from the first millennium enumerate various demons and personified agents of disease, but a considerable portion of the terms in such lists belongs to the repertory of the descriptive or metaphorical disease names discussed earlier, which can range from general terms for sickness to specific conditions dealt with in the medical texts. ${ }^{84}$ Some of the ailments in the lists embedded in incantations could represent common ailments that were also widely recognised among people (comparable to the 'popular illness entities' described by Olivier de Sardan 1998, 1999), ${ }^{85}$ while others are linked to complex and technical fields of knowledge concerning nosology and therapy, which only the healing specialist would be versed in and able to master.

\section{Tendencies towards systematisation: medical compendia in first millennium BCE Mesopotamia}

One of the much discussed developments in Mesopotamian technical literature, especially in the fields of divination, medicine, magic, rituals and cult songs (but also in lexicography), is the formation of text collections or compendia organised in the form of 'series' (ǐ̌k $\bar{a} r u$ ) - a process of text collecting and editing that must have started already in the second millennium BCE at different places in Babylonia and Assyria, but is best documented through the first millennium texts. ${ }^{86}$ The tablets recovered from Ashurbanipal's royal library at Nineveh give impressive evidence of an extensive collection of scholarly texts, including serialised compendia of incantations, healing rituals and medical prescriptions, copied, assembled and edited by different teams of scholars. But similar efforts took place at other cities such as Assur, Babylon, Borsippa or Uruk. Among these texts are two medical compendia which can be regarded as systematic and comprehensive representations of specialists' knowledge about all kinds of conditions: the Diagnostic Handbook (Sakikk $\hat{u}$ ) and the Corpus of Therapeutic Prescriptions. As we know from extant manuscripts and from two catalogues listing for each work a fixed sequence of component tablets by their titles, both compendia were subdivided into sections (sub-series or treatises) consisting of varying numbers of individual tablets (or chapters). ${ }^{87}$ Each section and individual tablet of the two compendia had a thematic focus on specific groups or aspects of disease, as can be inferred from the titles of the tablets and from our (still quite incomplete) knowledge of extant manuscripts. Our most important document for the organisation of the Corpus of Therapeutic Prescriptions forms a catalogue of incipits from the city of Assur, the so-called Assur Medical Catalogue (AMC), dating to the eighth or seventh century BCE, which gives an overview of the thematic sections of the whole corpus of medical therapies, dividing it into two series (each with its 
own title), together comprising more than 90 tablets. The first of the two series is known best through text witnesses from Nineveh (the so-called Nineveh Medical Compendium $).{ }^{88}$

Both the Corpus of Therapeutic Prescriptions listed in the Assur Medical Catalogue and the Diagnostic Handbook (likewise described in a corresponding series catalogue) exhibit an organisation of contents based on typologies of conditions. Although often including quite heterogeneous material, the formal organisation of both compendia allows us to assign a descriptive term or heading to each of their sections, which provides a more or less tentative identification of a section's overall topic, illustrated through the schematic overview of both compendia in Figure 6.1.

A comparison brings to light a number of similar organisational principles and topics in the Diagnostic Handbook and the Corpus of Therapeutic Prescriptions. Both works contain sections organised anatomically as well as non-anatomical sections focusing on a limited topic or a group of diseases. In both compendia, we find several corresponding topics or sections, some of which show striking resemblances which suggest that the redaction of the therapeutic material was inspired by and partially followed the model of the Diagnostic Handbook. Moreover, occasional textual parallels between passages in both compendia indicate processes of exchange and borrowing. ${ }^{89}$

To point out a few overlapping topics in the two compendia, both contain sections on women (concerned with pregnancy, birth and gynaecology) and on sexuality (dealing e.g. with potency or sexual arousal), both found towards the end of the compendia. ${ }^{90}$ Sections in the Diagnostic Handbook that seem to contain incursions from the therapeutic texts are found in sections IV and V, indicated by instances of identical or similar tablet incipits, and by the focus of some of the tablets on conditions that are extensively treated in therapeutic texts. ${ }^{91}$ Sections IV and V of the Diagnostic Handbook are also unusual because a number of tablets contain treatments (unlike the rest of the Diagnostic Handbook). ${ }^{92}$ However, remarkable differences between both compendia are discernible as well. While the Diagnostic Handbook included a tablet on paediatrics (the concluding Tablet 40), there is no exclusive section devoted to infants' conditions in the Corpus of Therapeutic Prescriptions; however, comments in the AMC show that treatments for children's ailments were integrated into other thematic sections (e.g. remedies for children suffering from cough). Interestingly, the last section of the AMC lists a tablet on veterinary medicine (dealing e.g. with epidemics), while the Diagnostic Handbook deals exclusively with conditions affecting the human body. Another noteworthy phenomenon in both compendia is the inclusion of textual material that is not strictly 'medical', i.e. not concerned with observations of symptoms or with medical therapy, but is more closely related to the realm of divination or oracles. Thus, Tablets 1-2 of the Diagnostic Handbook list observations made by the healer on his way to the patient and observations in the house of the patient, which served as signs that allowed the healer to make predictions about the patient's chances of recovery even before setting eyes on him/her (George 1991). In addition, the Assur Medical Catalogue includes a section (dubbed ORACLES), which 
The Diagnostic Handbook (SA.GIG 'sick sinews'; 'symptoms')

Ominous signs on the way to / in the house of the sick person

Symptoms "from the top of the head to the feet":

Skull; Hair

Temples

Eyes

Nose

Mouth, tongue; voice

Ears

Face

Neck and Throat

Hands and Fingers

Chest and back

Belly

Hips, penis, anus, legs, knees, feet

III

Temporal and dynamic aspects of illness:

Duration; stages; times; age of the patient; Changes of temperature; fevers; discolorations; excreting body fluids; ingesting food; movements and behaviour of the patient; signs in the vicinity of the patient

Epilepsy and other neurological conditions: Falling (sickness), epileptic fits, strokes (mišittu), transformations of epilepsy forms; attacks of demons (with occasional remedies - medicine bags, salves, rituals)

Common types of illnesses:

Treatments for himiț șêti 'burning of sunheat' and šibiț šāri 'wind-blasting', Skin diseases, ailments of joints/muscles, bones; jaundice Potency and libido

\section{Women and Infants:}

Pregnancy prognoses; complications during pregnancy; symptoms during and after birth;

Infant diseases
The Corpus of Therapeutic Texts (Assur Medical Catalogue)

PART 1: 'Remedies (for illnesses) from the top of the head to the (toe) nails'

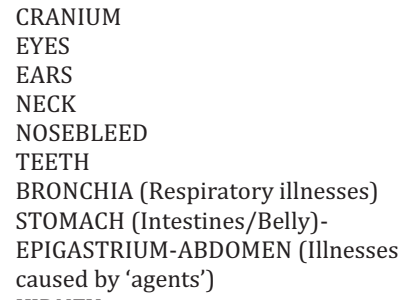

PART 2: '[If the skin lesion ...]... is swollen' SKIN

XIV HAZARDS (Illnesses caused by animals, injuries, battle wounds)

EVIL POWERS (Illnesses caused by witchcraft and demons)

XVI DIVINE ANGER (Illnesses caused by divine anger, oath, witchcraft)

XVII ORACLES

XVIII MENTAL ILLNESS (depression, epilepsy, ...)

XIX POTENCY

XX SEX (Male-female relations; illnesses caused by succubus/incubus demons)

XXI PREGNANCY (Protective rituals for families and pregnant women)

XXII BIRTH (and women's ailments)

XXIII VETERINARY

Figure 6.1 The thematic structure of the Diagnostic Handbook and the Corpus of Therapeutic Prescriptions 
may have been concerned with similar ominous signs observed in the environment or with procedures to procure an oracle concerning the patient's recovery (Steinert et al. 2018: 257-8).

A brief overview of the different sections of the Diagnostic Handbook and their topics allows us to point out a few observations concerning the underlying classification of different pathologies in this compendium, which we can compare with the arrangement of topics in the Corpus of Therapeutic Prescriptions. The contents of the individual tablets of the Diagnostic Handbook often consist of several ruled-off sections of related material, and some sections are arranged by an overarching ordering principle paralleled in therapeutic texts. For instance, the arrangement of diagnostic entries following the anatomical principle 'from head to foot' was applied throughout the 12 tablets of section II (Tablets 3-14) in the Diagnostic Handbook, and also Part 1 of AMC witnessed in the tablets of the Nineveh Medical Compendium was arranged in this fashion, likewise comprising 12 sections (I-XII) which are described as 'remedies from the top of the head to the (toe)nails'. Both the 'anatomical' sections of the Diagnostic Handbook and the Nineveh Medical Compendium devote several tablets or sections to the parts of the head followed by the other areas of the body, but the main difference between them is that the contents within each section of the Nineveh Medical Compendium are organised according to different treated conditions or central leading symptoms, while Tablets 3-14 of the Diagnostic Handbook are arranged in a more detailed and stringent anatomical fashion, reflecting the central aim of the âšipu's diagnostic procedure, to identify the underlying cause or causative agent for any given symptom on any part of the body. ${ }^{93}$

The third section of the Diagnostic Handbook (Tablets 15-25) is concerned with various temporal or dynamic aspects of disease, such as the duration of symptoms, the moment at which a condition began to manifest, and recurring or cyclical patterns of symptoms. Noteworthy features are, for instance, that Tablet 15 deals with symptoms manifesting on the first day of an illness and on various body parts (from head to toe), which receive a lethal prognosis, while Tablet 16 is concerned with longer periods of sickness (from two days up to several months) and with conditions observed in old age. Tablets 17 and 18 have several thematic foci related to temporal and dynamic aspects of disease, such as symptoms occurring at the beginning and during the course of an illness, at specific times of the day, as well as discolorations and changes in body temperature. Tablets 19-20 concern high temperatures and perspiration at different times of the day and throughout the year. Noteworthy is also Tablet 22, which deals with symptoms focusing mainly on conspicuous mood and behaviour patterns of the patient ranging from strange movements and emotional upset ('love sickness') to symptoms such as depression and altered mental states. Likewise of interest are the topics of Tablets 23-24, which focus on the ingestion of different foodstuffs by the patient, their desire for different foods and on bodily emissions via mouth/nose (vomiting, bleeding).

The fourth section of the Diagnostic Handbook (Tablets 26-30) is reserved for various forms of epilepsy and related conditions, which are of particular insight with regard to culture-specific classifications. Tablet 26 starts with symptom 
descriptions for specific forms of seizures and epileptic attacks (miqtu 'fall', hay(y)attu 'terror' (a state of confusion), șibtu 'seizure') occurring at different times. A considerable number of the diagnoses in Tablet 26 refer to AN.TA.ŠUB. BA and the 'wind' demons lilî, lilìtu and ardat lilî (incubus and succubus), the latter of which often seem to be associated with seizures, confusional states and abnormal behaviour patterns:

\section{Diagnostic Handbook Tablet 26: 14, 48'-49' (Heeßel 2000: 279, 282, 287, 289; Scurlock 2014: 196, 198, 201, 203)}

If when (a 'fall') falls upon him, he turns pale and laughs a lot and his feet (var. his hands and his feet) are continually contorted, (then it is) 'Hand of a lilu-demon'.

If it afflicts him in his sleep, and he looks at the one who afflicts him, it 'flows' over him and he forgets himself, he trembles (with fear) when they have awakened him (but) he can (still) get up, ..., (then it is) 'Hand of false lilû'. For a woman, (it is due to) a lilu-demon.

Tablet 27 begins with entries concerning 'stroke' (mišittu) that affects different parts of the body and continues with sections arranged by diagnosis and grouped around different demonic agents of epilepsy/seizures (gall $\hat{u}$-demon, al $\hat{u}$-demon, the 'lurker of the river', ghosts). It is worth noting that stroke is particularly linked with two demons (the 'lurker' (rābișu) and the demon of the lavatory, Šlak); the other sections give characteristic symptoms that allow differentiation between each of the causing agents: the gall $\hat{u}$-demon causes symptoms similar to AN.TA.ŠUB.BA ('flowing over' the patient) such as rolling back the eyes, while the alv is associated e.g. with stupor falling on the patient and the 'lurker of the river' with epileptic attacks during bathing. Tablet 28 discusses various transformations of different 'epilepsy' forms into one another, each of which is diagnosed as being caused by a deity and combined with a therapeutic instruction (medicine bags worn around the neck), followed by a section interpreting visions of the patient during prolonged illness. Tablet 29 takes into view the epilepsy forms 'Lord of the roof' and 'spawn of Šulpaea', which are differentiated according to the age of the patient at the first occurrence of the attacks (from birth and infancy to adulthood), appending a therapeutic recommendation (mostly amulets, ointments); in the latter part of the tablet, different times and localities of an epileptic attack of AN.TA.ŠUB.BA are taken into account. ${ }^{94}$ Tablet 30 possibly continued with related conditions attributed to divine senders (Scurlock 2014: 223; Stadhouders 2011: 39-51). Section IV of the Diagnostic Handbook is remarkable as a whole, since it appears to delimit a specific class of diseases that we would recognise as largely neurological or psychiatric. However, with regard to their predominantly 'demonic' character and aetiologies, the conditions grouped there are also closely comparable with possession disorders discussed in anthropological literature. ${ }^{95}$ It is noteworthy that the compendium in Part 2 of the Assur Medical Catalogue contains a section (MENTAL ILLNESS) concerned 
with treatments for very much the same set of conditions as found in section IV of the Diagnostic Handbook. ${ }^{96}$

The fifth section of the Diagnostic Handbook (Tablets 31-35) is likewise striking in comparison with the arrangement of topics in the Corpus of Therapeutic Prescriptions. Tablet 31 is concerned with himit șe ti 'burning of sun-heat' (used interchangeably with the term șetu 'sun-heat'), a type of febrile condition paired with various other symptoms, which is also an important topic of the section STOMACH in Part 1 of the Corpus of Therapeutic Prescriptions treating gastrointestinal ailments. ${ }^{97}$ In contrast to the therapeutic texts on șêtu-fever, Tablet 31 of the Diagnostic Handbook is particularly interested in determining the duration of different episodes of șêtu (lasting between 3 and 52 days) on the basis of specific symptoms, appending a therapeutic instruction for each case to assure that the patient would not stay ill longer than the given period. The described cases and therapeutic instructions given there (mostly ointments and potions) actually share a number of similarities and occasional overlaps with prescriptions for șêtu in STOMACH Tablet 4, which recommend ointments, potions, special foods and emetics as therapy (cf. Heeßel 2000: 342-7; Johnson 2014: 29-33). Tablet 32 of the Diagnostic Handbook, only known from its catalogue incipit, also concentrated on gastrointestinal ailments, as is indicated by the keyword 'wind blasting' (associated with bloating and gas retention), likewise paralleling entries in therapeutic tablets related to the section STOMACH. ${ }^{98}$ Tablet 33 is a unique tablet in the Diagnostic Handbook divided into two parts, which seem to provide two theoretical layers of medical diagnosis. The first part of the tablet identifies the main symptoms of a set of specific conditions, covering a seemingly random selection of ailments of the skin, the joints/muscles, fevers, jaundice and other ailments that may represent common types of conditions, since most of them are familiar from the therapeutic texts. The second part of Tablet 33 presents a kind of chart providing an equation for the conditions in the first part with a divine agent regarded as sender of the complaints, which looks like a 'conjurer's' interpretation within the theoretical framework of his discipline of conditions, to which 'physicians' may traditionally have attributed other causes focusing on environmental factors. ${ }^{99}$ However, first millennium BCE therapeutic texts on skin conditions likewise offer examples for the same diagnostic formulary equating disease names with the 'Hands' of deities as in Diagnostic Handbook Tablet 33, suggesting that both healing disciplines worked with personalising aetiologies, at least in this period. ${ }^{100}$ From a classificatory angle, Tablet 33 could be understood as a systematisation of disorders bearing names that do not imply an underlying causing agent, by assigning a specific deity responsible for them. ${ }^{101}$ The last tablets of section V, Tablets 34 and 35, are only known from their catalogue incipits, which suggest that they may have focused on topics having parallels with the sections POTENCY/SEX in the Assur Medical Catalogue concerned with problems relating to sexuality and with conditions attributed to sorcery (e.g. impotence). It could be suspected that section V of the Diagnostic Handbook contains further links to the Corpus of Therapeutic Prescriptions, e.g. to the sections EVIL POWERS and DIVINE 
ANGER focusing on demonic and divine causes of sickness and misfortune (cf. Steinert et al. 2018).

The last section of the Diagnostic Handbook is reserved for specialised topics related to women's and children's health (Tablets 36-40). Tablet 36 focuses on prognoses concerning pregnant 'fertile women', making predictions about the woman's health and the chances of survival for the baby by drawing on the appearance of her body and her behaviour. As implied by the incipits, Tablets 37-39 were concerned with women's conditions in particular, in the context of pregnancy and birth. Tablet 40 lists symptoms observed in (suckling) infants, loosely arranged by diagnoses. The sequence of incipits and contents of the sections PREGNANCY and BIRTH in the Assur Medical Catalogue reflect a similar progressive arrangement of topics. From a medical point of view, the main topics of these sections concern gynaecology and obstetrics (miscarriage, loss of amniotic fluid or bleeding during pregnancy, delay of delivery, difficult delivery, postpartum conditions, gynaecological haemorrhage, abnormal genital discharge) while at the same time throwing light on aetiologies underlying some of these problems. Thus, the incipits and textual sources point out that miscarriage, infant death and problems during and after delivery could be caused by deities (e.g. the healing goddess Ninkarrak), demons (Lamaštu) and sorcery. The therapies applied for these problems range from medical treatments (e.g. tampons, potions) to protective measures (amulets), incantations and rituals, often prescribed in combined fashion, addressing both physical complaints and underlying causes of sickness (cf. Steinert et al. 2018 for discussion).

Both the Diagnostic Handbook and the Corpus of Therapeutic Prescriptions outlined in the Assur Medical Catalogue reflect efforts to classify and group related conditions, although the principles of classification are rarely made explicit (as in the case of the 'head to foot' arrangement of conditions in the Nineveh Medical Compendium (AMC Part 1) and in section II of the Diagnostic Handbook). The Diagnostic Handbook with its six broadly thematic sections (or sub-series) reflects the intention to enable the practitioner to approach the patient's symptoms and his search for a diagnosis and prognosis from different angles at the same time, presenting and arranging groups of diagnostic entries either from an anatomical perspective or through a thematic organisation of contents based on associated symptoms, related groups of conditions or similar diagnoses and prognoses. Every tablet within a sub-series often has a core topic, and each tablet is further divided into ruled-off sections of related entries. Within the ruled-off text sections, which are often held together by a common keyword or phrase, one can often notice an underlying intention for differentiation between closely related conditions, but sequences of entries and ruled-off sections can also be loosely associative. Similar principles of thematic organisation were applied in the Corpus of Therapeutic Prescriptions, but here text sections can also be arranged by grouping together prescriptions or entries by treatment type (potion, ointments etc.) or several spells for the same or closely related conditions. 


\section{Is there a 'system of correspondence' in Mesopotamian medicine?}

The growing tendency of Mesopotamian specialists in the first millennium BCE to systematise their knowledge of different disorders and pathologies, their underlying causes and treatments ${ }^{102}$ may possibly be linked with other elements pointing towards a culture-specific version of an incipient 'system of correspondences' comparable to similar theoretical systems encountered. The framework of the five phases in Chinese medicine or the system of the four humours in Greek medicine are other examples that come to mind. ${ }^{103}$ The Greek system knows four humours which correspond not only to four internal organs, but also to the elements (air, fire, earth, water), mixtures of the qualities hot-dry-coldmoist, to seasons, times of the day, life stages (childhood, youth, maturity, old age), colours, tastes, planets and zodiac signs, psychological temperaments and types of disorders. In Chinese medicine, we encounter very similar and complex correlations: here, five viscera correspond with five agents (wood, fire, earth/ soil, metal, water) and are further correlated for instance with colours (bluegreen, red, white, black, yellow), cardinal directions (east, south, west, north, centre), seasons (spring, summer, late summer, autumn, winter), flavours, body parts and complaints in specific body parts (head/neck, chest/flanks, shoulder/ back, waist/thigh, spine). ${ }^{104}$

Similar tendencies towards developing systematic correspondences in the context of Mesopotamian diagnosis (attested also for other branches of divinatory interpretation and prognostication) can predominantly be grasped in texts connected to the profession of the 'conjurer' ( $\bar{a}$ šipu), whose knowledge and expertise embraced virtually all important fields of scholarly learning in the first millennium BCE, although traces of such systematisations can also be found in the therapeutic texts linked with the as $\hat{u}$ 'physician'. The previous section already discussed the thematic sections and underlying classes of diseases in the Diagnostic Handbook, which was used by the āšipu for establishing a diagnosis and prognosis. This work is an important witness for scholarly attempts to establish systematic links between signs/symptoms of the body and powers, forces and processes in the environment, with the ultimate aim of identifying the cause of (or agent causing) each ailment in question. The numerous entries in the Diagnostic Handbook not only describe various properties of body parts, morbid processes, abnormal behaviour patterns and their changes and transformations, but also take into account contextual factors such as time, place or age of the patient, as well as external influences such as winds, weather and seasons. ${ }^{105}$

Several sequences of diagnostic entries in tablets of the Diagnostic Handbook betray the application of certain schemata and principles of interpretation, such as word play (paranomasia) and different kinds of associations based on the correlation between sets of symptoms and groups of aetiological diagnoses (Heeßel $2000,2004 b$ ). For instance, we find sets of diagnostic entries grouped together, in which combinations of symptoms affecting body parts are associated with different deities causing these symptoms: 


\section{Diagnostic Handbook Tablet 3: 17-20 (cf. Scurlock 2014: 13-14, 19)}

If a man keeps crying out 'My skull, my skull!': 'Hand of Anu', in the evening (he has been struck).

If he is 'struck' on his skull: 'Hand of Papsukkal' . . .

If he is 'struck' on his skull and his ears do not hear: 'Hand of Ištar' for a gift (that she desires from the patient).

If he is 'struck' on his skull and his legs, arms and stomach continually afflict him: affliction by [...].

The passage focuses on the key symptom 'being hit' on the 'skull' or top of the head (muhhu). Intense pain in this area is attributed to Anu, the god of heaven and head of the Babylonian pantheon. Being 'struck' on the skull (possibly referring to injury or trauma) is assigned to Papsukkal, the vizier of Anu. The next entries take into account additional symptoms such as hearing loss, which is equated with the 'Hand of the goddess Ištar' (Venus). A similar pattern is seen in the association of certain colours or directions, such as left and right, with causing deities:

\section{Diagnostic Handbook Tablet 14: 175'-180' (Scurlock 2014: 124-5, 133)}

[If the right side of his abdomen] hurts him: 'Hand of his god', he will get well.

[If the left side of his abdomen] hurts him: 'Hand of his goddess', he will get well.

[If the right side of his abdomen] is swollen and dark and he wanders about without knowing (it): ['Hand of the god Adad']. (If) he was 'struck' at noon, he will die.

If the left side [of his abdomen] is swollen and dark and he wanders about without knowing (it): ['Hand of the goddess Ištar']. (If) he was 'struck' in the morning, he will die.

Here, symptoms in the area of the abdomen are grouped in two pairs of entries. Less severe symptoms with a positive prognosis are attributed to the personal deities of the patient, while dangerous, life-threatening symptoms are attributed to a pair of deities with destructive powers, the weather-god Adad and the goddess of sexuality and war Ištar (the morning/evening star Venus). The entries employ the polarity of right and left in the protasis, to which the values male and female are assigned in the apodosis (the last two entries add an association with two different times of the day). ${ }^{106}$ In other instances, we may encounter even more complex or layered correlations between specific symptoms or nosological entities (that are at times associated with natural forces) and divine agents causing them. Such correspondences are exhibited for instance in the context of skin conditions, dealt with in Tablet 33 of the Diagnostic Handbook (but therapeutic texts concerned with skin diseases offer similar examples). For example, an entry in the first part 
of the tablet discusses a lesion which looks similar to 'pustules' (bubu'tu) and is accompanied by a reddening of the skin, which is identified with the condition 'wind blasting'. Interestingly, therapeutic texts focusing on symptoms of the genital organs (e.g. morbid discharge) mention pustules on the penis as a consequence of wind having 'blasted' the patient's penis, thus implicitly assigning an environmental cause to the ailment: ${ }^{107}$

\section{Diagnostic Handbook Tablet 33: 26 (Heeßel 2000: 354, 360; Scurlock 2014: 232, 237)}

If the appearance of the lesion is like pustules and his body is red, it is called 'wind blasting' (šibit šāri).

The second part of Tablet 33 assigns an underlying (hidden) cause to the conditions described in the first part of the tablet. Here, pustules (bubu'tu) of different colour are correlated with a set of divine agents often associated with skin conditions and 'diseases of intercourse': 108

\section{Diagnostic Handbook Tablet 33: 113-114 (Heeßel 2000: 358, 363; Scur- lock 2014: 235, 240) \\ White pustules: 'Hand of (the sun god) Šamaš', he will get well. \\ [Black pustules]: 'Hand of Ištar' (Venus); touch of the Fate-Demon; he will not get well. \\ Red pustules: 'Hand of (the moon god) Sîn'; ditto (he will not get well).}

Here, varieties of the same type of skin lesion are correlated with members of a divine family also representing heavenly planets: sun-god and Venus-goddess are children of the moon-god Sîn. A similar case of layered diagnosis is encountered in a therapeutic text on skin ailments:

\section{BAM 580 iii 15'-17', 20'-22' (cf. Scurlock 2014: 550-1)}

If a lesion ditto (comes out of a man's body which) has been itching since the beginning (of the illness), the inside of which is full of sikkatu (peg-like secretions) and when they open up, it is hot and flows, then it is called 'male sluice (gate) fly'. (If) wind has blasted him (the patient), it is 'overwhelming by the god Pabilsag'.

If a lesion ditto (comes out of a man's body which) does not hurt him, appears (only) on the surface of the skin and when it opens up, plenty of pus flows (from it), then it is called 'female sluice (gate) fly'. (If) wind has blasted him (the patient), it is 'overwhelming by the twin gods'.

This passage describes the symptoms of two varieties of suppurating skin lesions differentiated as male and female type of the condition (cf. Steinert 2016: 21617). The name of the ailment, lamsat hilatati, is also known as the name of an 
insect, literally 'sluice (gate) fly'. The name plays with several associations: the sluice serves as a metaphor for suppuration, while the insect evokes ideas of bites or stings causing characteristic symptoms such as itching and pain. In addition to the diagnosis lamșat hìlāti alluding to environmental imagery, a second diagnosis is given which takes into account the factor that the patient's symptoms were caused by wind that has 'blasted him', but attributes this external influence to different deities and stellar manifestations: Pabilsag (the consort of the healing goddess Gula) is equated with the zodiac sign Sagittarius; the 'twin gods' are equated with Gemini.

Similar correlations can be observed in diagnostic entries concerned with temporal aspects of illness episodes, where specific days, times of the day or time periods can play a role in diagnosis and are associated with deities. ${ }^{109} \mathrm{Such}$ examples reflect links between the diagnostic texts and the traditions of calendar omens (hemerologies/menologies), which also formed part of the professional corpus of the conjurer. ${ }^{110}$ Thus, hemerological texts give recommendations for diet, behaviour and avoidances during specific months and days of the calendar (which are divided into lucky and unlucky days), warning that certain actions should be avoided on certain dates so as not to trigger divine anger or to contract certain diseases. Traditions and regulations of the calendar texts (e.g. the association of days with deities) may thus have contributed to some aetiological diagnoses.

\section{Astro-medicine}

Another factor that contributed to the beginnings of a 'system of correspondences' in Mesopotamian medicine in the first millennium is the rise of astromedicine (medical astrology), which is linked to the growing importance of astrology in that period and to innovations such as the zodiac and horoscopes. ${ }^{111}$ Astro-medicine is based on the idea of correlations between the body, processes of health, disease and cyclical or periodic events in the celestial realm. The principle of these correlations is explicitly expressed in divination manuals commenting that events ('signs') on earth and in the heavens (movements of stars, constellations and planets) mirror each other, i.e. all domains of life and the cosmos are linked and interrelated. ${ }^{112}$ During the first millennium BCE, the older idea that the stars (often understood as manifestations of the gods) exert an influence on health and on medicinal substances or that diseases descend from the stars, is expanded into a system of calendrical correlations between stars, planets, zodiac signs (associated with gods and months) and classes of things relevant in medicine and healing, such as body parts, pathological symptoms and categories of materia medica (stones, plants, woods). ${ }^{113}$ These correlations form a new layer that was fused with older elements of the system of diagnosis, prognosis, therapy and prophylaxis. What is remarkable about the approach of astro-medicine is that it is tied to the idea of regularity and predictability of events in the cosmos, while the notion of a general link between different phenomena and domains of the world is an older, fundamental concept in Mesopotamian divination and 
cosmology. On the other hand, astro-medicine added to the complexity of the traditional system of nosology and healing.

The tablet BM 56605 from the Hellenistic or Parthian period illustrates the complex interlinkage between different elements of the astro-medical 'system' (Heeßel 2000: 112-30, 468-9, 2008: 11-14; Wee 2015). The obverse of the tablet contains a section of diagnostic entries known from Tablet 29 of the Diagnostic Handbook (on epilepsy befalling a patient at various times) paired with an appropriate therapy, which is followed by a sequence of entries focusing on cases that different stars 'touch' the patient during an illness episode(?) causing pain in various body parts, which is to be treated with an ointment and with medicine bags wrapped in different kinds of animal skin. Each star causes pain in a specific body part, which is reflected in the choice of corresponding ingredients in the prescriptions. A representative entry from this passage reads:

\section{BM 56605 obv. 48-50 (Heeßel 2000: 119, 122, 124-6)}

If during ditto (i.e. an illness episode?) the 'Great star' (Aquarius) touches the sick man and his right thigh hurts him: you put cypress (wrapped) in cat skin around his neck, you anoint him with oil and he will recover. ${ }^{114}$

On the reverse of BM 56605 (see Figure 6.2), we find an astrological table presenting a chart of the zodiac signs (row 1), body parts (row 2), followed by rows of micro-zodiacal divisions consisting of the numbers 1-12 (in a diagonal arrangement), each combined with the name of an object (a star constellation or therapeutic agent) in each field (Heeßel 2000: 128-30, 469, 2008: 14; Wee 2015: 224-6 with Fig. 2).

The sequence of body parts is given in a vertical head-to-feet order, thus presenting the first attestation for the scheme of zodiacal melothesia, which is later attested in very similar form in Graeco-Roman and later texts (Table 6.1) (Geller 2014; Wee 2015).

This remarkable scheme can be compared with the 12 chapters of the Nineveh Medical Compendium, which are likewise organised by body parts or regions (see Figure 6.1 Assur Medical Catalogue Part 1), as are the 12 Tablets 3-14 of the Diagnostic Handbook. The table on the reverse of BM 56605 could have been used to choose one of the therapies listed in the fields on the right-hand column, which correlate a zodiac constellation with a stone, a plant and one type of wood followed by a hemerological recommendation pertaining to days in the month of the relevant zodiac sign:

\section{BM 56605 rev. i 1-2, 5-6 (Heeßel 2000: 129)}

The Hireling (Aries) (corresponds to) zânu-stone, mēsu-wood, imhur-lìmplant. On the 20th of the month Nisannu you shall not eat fish or leek. 


\begin{tabular}{|c|c|c|c|c|c|c|c|c|c|c|c|c|}
\hline$\gamma$ & $\gamma$ & II & $\sigma$ & $\Omega$ & me & $\Omega$ & $m$ & $x^{7}$ & $y_{0}$ & $m$ & H & Materia \\
\hline Bo & & 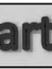 & & & & & & & & & & medica \\
\hline 1 & 2 & 3 & 4 & 5 & 6 & 7 & 8 & 9 & 10 & 11 & 12 & \\
\hline 2 & 3 & 4 & 5 & 6 & 7 & 8 & 9 & 10 & 11 & 12 & 1 & \\
\hline 3 & 4 & 5 & 6 & 7 & 8 & 9 & 10 & 11 & 12 & 1 & 2 & \\
\hline 4 & 5 & 6 & 7 & 8 & 9 & 10 & 11 & 12 & 1 & 2 & 3 & \\
\hline 5 & 6 & 7 & 8 & 9 & 10 & 11 & 12 & 1 & 2 & 3 & 4 & \\
\hline 6 & 7 & 8 & 9 & 10 & 11 & 12 & 1 & 2 & 3 & 4 & 5 & \\
\hline 7 & 8 & 9 & 10 & 11 & 12 & 1 & 2 & 3 & 4 & 5 & 6 & \\
\hline 8 & 9 & 10 & 11 & 12 & 1 & 2 & 3 & 4 & 5 & 6 & 7 & \\
\hline 9 & 10 & 11 & 12 & 1 & 2 & 3 & 4 & 5 & 6 & 7 & 8 & \\
\hline 10 & 11 & 12 & 1 & 2 & 3 & 4 & 5 & 6 & 7 & 8 & 9 & \\
\hline 11 & 12 & 1 & 2 & 3 & 4 & 5 & 6 & 7 & 8 & 9 & 10 & \\
\hline
\end{tabular}

Figure 6.2 BM 56605 reverse

Source: after Wee 2015: 226 Fig. 2

Table 6.1 BM 56606 rev. rows 1-2, correlations between zodiac signs and body parts (after Wee 2015: 227 Table 2)

\begin{tabular}{|c|c|c|c|}
\hline Column & $\begin{array}{l}\text { Zodiacal sign } \\
\text { (row 1) }\end{array}$ & $\begin{array}{l}\text { Body part } \\
\text { (row 2) }\end{array}$ & Translation \\
\hline 1 & Aries & ${ }^{\top} \mathrm{SAG}^{\top}$ & Head \\
\hline 2 & Taurus & 'x’ GU' & . . Neck \\
\hline 3 & Gemini & Á 'MAŚ.SİL" & Arm, shoulder \\
\hline 4 & Cancer & ${ }^{\circ} \mathrm{GABA}^{\top}$ & Chest \\
\hline 5 & Leo & ${ }^{\top} l i b-b i^{\top}$ & Heart/belly \\
\hline 6 & Virgo & $\mathrm{GU}_{4} \cdot \mathrm{MURUB}_{4}$ & Waist \\
\hline 7 & Libra & HAR(?) & Insides/liver(?) \\
\hline 8 & Scorpio & $\mathrm{PES}_{4}$ & Female genitalia \\
\hline 9 & Sagittarius & TUGUL & Hip/upper Thigh \\
\hline 10 & Capricorn & kim-șa & Knees/shins \\
\hline 11 & Aquarius & ÚR & Leg \\
\hline 12 & Pisces & 'GÌR.2` & Feet \\
\hline
\end{tabular}


The Great Twins (Gemini) (correspond to) carnelian, suādu-wood, kamkaduplant. On the 15 th of the month Simanu you shall not drink milk. ${ }^{115}$

The scheme of the 'zodiac man' with 12 body parts is not the only example for correlations between the human body and heavenly bodies. There are also hints for associations between planets and internal organs, as is pointed out by a Late Babylonian medical commentary that equates pain in the spleen with Jupiter and pain in the kidneys with Mars (Civil 1974: 336-7 Text 3; Reiner 1995: 60).

\section{The 'four organ-system'}

Our last piece of evidence for the systematisation of medical knowledge in the Late Babylonian period is found in a unique text discovered at Uruk in the tablet collection of a family of conjurers (Figure 6.3). ${ }^{116} \mathrm{SpTU} 1,43$ has sparked considerable interest and discussion in Assyriological research because it can be compared with the system of the four humours in Greek medicine and with the five agents/phases in China. The tablet presents a list correlating groups of diseases with four internal organs from which these conditions originate: from the heart (libbu), the stomach (karšu, more precisely the two 'mouths' of the stomach), the lungs (haš $\hat{u})$ and kidneys (kalâtu). However, in contrast to the 'cosmological' equations found in Greek and Chinese medicine, a connection of the organs with environmental or cosmic phenomena such as seasons, elements or directions is not drawn in SpTU 1, 43. The text thus seems to present a nosological 'skeleton model' without cosmological correlations, but it is possible that the four organs were linked with four three-month quarters of the year (corresponding to the four/ five seasons in Greece and China).

The 'disease taxonomy' in SpTU 1, 43 lists only a selection of conditions known in Babylonian medicine, but the correlations betray a clear tendency to systematise pathological processes and to link them with anatomical structures and their associated functions. The four groups of disorders are tied to the understanding of the functions of internal organs, which is based on traditional concepts in Mesopotamian culture relating to internal organs as the locus of the self, emotions and consciousness as well as physiological processes. But SpTU 1, 43 also offers novel and sophisticated associations not known from other medical texts, e.g. the idea that female infertility (the womb that is twisted) is influenced by the kidneys, which are in this text portrayed as the organ ruling over the processes in the lower body.

It is remarkable that in SpTU 1, 43 the heart (libbu) is associated exclusively with psycho-neurological or mental conditions including different types of epilepsy, seizures and the ailment 'heartbreak' ( $h \bar{i} p$ libbi), a group of conditions well known from section IV of the Diagnostic Handbook as well as from therapeutic texts (cf. Figure 6.1 AMC section MENTAL ILLNESS). The physiological assignment of these conditions to the organ 'heart' in SpTU 1, 43 is a novel idea, although the 'heart/belly' (libbu) traditionally belongs to the inner organs of the body which in Sumerian and Akkadian texts are commonly described as the seat of emotions and mental processes. ${ }^{117}$ Interestingly, the Corpus of Therapeutic 
SpTU 1, 43 (Hunger 1976: 50-51; Geller 2014: 3-6)

\begin{tabular}{|c|c|c|}
\hline 1 & From the heart $(l i b b u)$ : & Heartbreak (depression). \\
\hline 2 & Ditto (= from the heart): & $\begin{array}{l}\text { 'Fallen-from-heaven (disease)' } \\
\text { (falling-sickness). }\end{array}$ \\
\hline 3 & Ditto: & 'Hand of the (personal) god'. \\
\hline 4 & Ditto: & $\begin{array}{l}\text { 'Hand of the (personal) } \\
\text { goddess'. }\end{array}$ \\
\hline 5 & Ditto: & bennu-illness (epilepsy). \\
\hline 6 & Ditto: & 'Lord of the roof' (epilepsy). \\
\hline 7 & From the "mouth of the stomach" (pi karši $)$ : & Head- and mouth-disease. \\
\hline 8 & $\begin{array}{l}\text { Ditto (from the 'mouth of the stomach'), of the } \\
\text { mouth: }\end{array}$ & $\begin{array}{l}\text { Tooth-(illness), bu'šānu } \\
\text { ('stench'). }\end{array}$ \\
\hline 9 & $\begin{array}{l}\text { Ditto, No. } 2 \text { (i.e. from the second 'mouth of the } \\
\text { stomach'): }\end{array}$ & {$[\ldots]$} \\
\hline 10 & Ditto, No. 2: & {$[\ldots]$} \\
\hline 11 & Ditto, No. 2: & $\begin{array}{l}\text { Bile ( } p a \bar{s} s i t t u) \text {, gallbladder } \\
\text { (ailment). }\end{array}$ \\
\hline 12 & Ditto: (i.e. from the 'mouth of the stomach') & Being full with water (dropsy). \\
\hline 13 & Ditto: & 'Hand of ghost'-illness. \\
\hline 14 & Ditto: & Maškadu (joint disease). \\
\hline 15 & Ditto: & Stroke. \\
\hline 16 & Ditto: & Ašû (a skin disease). \\
\hline 17 & Ditto: & Gișșatu (a skin disease). \\
\hline 18 & Ditto: & $\begin{array}{l}\text { 'Burning of sun-heat' (fever) } \\
\text { and all (similar) illnesses. }\end{array}$ \\
\hline 19 & From the lungs (hašû): & Throbbing (?). \\
\hline 20 & Ditto: & Cough. \\
\hline 21 & Ditto: & 'Winds'. \\
\hline 22 & Ditto: & ezezu-disease. \\
\hline 23 & Ditto: & bu'šānu ('stench'). \\
\hline 24 & Ditto: & sinnahtïru-respiratory disease. \\
\hline 25 & From the kidneys (kalâtu): & $\begin{array}{l}\text { Constriction (hiniqtu, of the } \\
\text { urethra?). }\end{array}$ \\
\hline 26 & Ditto: & $\begin{array}{l}\text { 'Arousal of the heart' (sexual } \\
\text { desire). }\end{array}$ \\
\hline 27 & Ditto: & Anal disease. \\
\hline 28 & Ditto: & $\begin{array}{l}\text { Sagallu-illness (of the lower } \\
\text { extremities). }\end{array}$ \\
\hline 29 & Ditto: & Infertility. \\
\hline 30 & Ditto: & The womb that is twisted. \\
\hline 31 & Ditto: & Retention of 'wind'. \\
\hline $32-36$ & $\begin{array}{l}\text { Written according to its original and collated. } \\
\text { 'Long tablet' of Rimūt-Anu, son of Šamaš-iddin, } \\
\text { descendent of (the) Šangû-Ninurta (family), the } \\
\text { conjurer. }\end{array}$ & \\
\hline
\end{tabular}

Figure 6.3 SpTU 1, 43 (fifth/fourth century BCE)

Prescriptions in the Assur Medical Catalogue contains two sections in which libbu is the key organ: section STOMACH deals with the 'belly' (libbu) in the context of gastrointestinal ailments, while the section MENTAL ILLNESS includes the ailment 'heartbreak' among the psychiatric and psychological conditions (cf. Figure 6.1). 
In the second section of SpTU 1, 43, the first, upper 'mouth' (opening) of the stomach is connected with 'head- and mouth-disease' and with ailments of the teeth and throat, while the 'second mouth of the stomach' (referring to the lower exit of the stomach into the duodenum) is associated with conditions attributed to bile or the gallbladder and with other internal conditions such as dropsy and 'burning of sun-heat (fever)'. Thus, the ailments in the second section of SpTU 1,43 correspond loosely with conditions clustered in the therapeutic treatises TEETH and STOMACH respectively.

The lungs in the third section of SpTU 1, 43 are grouped for instance with cough, winds and with bu'šănu 'stench', the latter of which is listed a second time among the disorders stemming from the first mouth of the stomach (which may be seen as a hint to an only vague differentiation between physiological processes connected to the respiratory and the gastrointestinal system, also indicated by the sequence of the sections BRONCHIA and STOMACH in AMC Part 1). ${ }^{118}$ To the kidneys SpTU 1, 43 assigns conditions in the lower body, such as renal and rectal diseases (resembling the sequence of the sections KIDNEY and ANUS in AMC Part 1), but also problems associated with the sexual organs (libido and female fertility/womb), a connection which is also encountered in the therapeutic section KIDNEY, but not in the gynaecological material.

While SpTU 1, 43 betrays new elements and an increased interest in the physiological causes of disease and in the functions of the organs, it also underlines the traditional orientation of a nosological system which classifies pathological conditions primarily according to anatomical location (from head to foot), but in which the idea of internal balance (e.g. balancing bodily humours or different kinds of vital energies) does not form an overarching concept to understand the body as a complex whole. Although we may see in this Late Babylonian text an indication for internalisation processes and for the systematisation of physiological aetiologies, the 'four organ-system' did not replace the personalising aetiologies so prominent in the Mesopotamian healing system. Yet, there are other hints for an increasing technical understanding of conditions attributed to 'Hands' of deities and demons and for a growing interest in determining environmental factors and regular cosmic patterns contributing to disease and to healing processes, even though the forces and powers behind these processes in the body and in nature were still ultimately linked with gods and their realms. An impetus to expand and systematise the knowledge of these interrelations can be grasped in several late texts discussed here, serving the needs of the healers to predict, diagnose, prognosticate and treat a broad range of health problems and give prophylactic recommendations to protect from sickness.

\section{Conclusion}

Seen through the lens of the cuneiform medical texts, one can describe Mesopotamian medicine as a multifaceted, complex conglomerate of ideas and practices that are characterised in some respects by a stability of traditions linked to definable healing professions or disciplines. But at the same time, the medical texts 
are characterised by diversity, varying local traditions and dynamic processes reflecting developments towards systematisation, which are tied to the formation of professional text corpora, to the serialisation of medical compendia and to the development of the different healing disciplines. The Babylonian system(s) of nosology and healing are thus better described as open, dynamic, diverse and flexible rather than completely consistent, uniform, stable and closed.

Our view of the Mesopotamian nosological concepts depends deeply on our perspective. Looking at the medical corpus as a whole through the first millennium compendia, these concepts appear quite systematic and stable, but when examining the various textual traditions and diachronic changes in the sources, Babylonian notions and classifications of diseases look more like a dynamic patchwork, a profuse and diversified ensemble of knowledge and practices. The textual material that has come down to us is far from uniform. First millennium medical series and compendia contain heterogeneous components and formularies that were not completely harmonised when they were compiled from different sources and varying traditions. Compendia such as the Diagnostic Handbook and the Corpus of Therapeutic Prescriptions are thus not monolithic. Moreover, the existence of variant local recensions of specific series (e.g. rituals), diverging versions of certain compositions (e.g. incantations) and differing compilations of medical prescriptions shows that there existed multiple textual traditions, locally varying nosological concepts and medical practices among the conjurers and physicians of Babylonia and Assyria.

From a diachronic perspective, we witness elements of stability, but also evolving textual traditions that are extended, reshaped or reinterpreted as well as innovative developments in medical concepts (e.g. the emergence of the 'four organ-system'). We also have to reckon with a variability in medical ideas and practices due to exchanges between the healing professions, contributing to the complex history of Mesopotamian medicine. Nonetheless, the textual sources discussed here have revealed a number of recurring principles and patterns of differentiating, grouping and classifying pathological conditions based on their anatomical locations, on observable symptoms and their characteristics (clinical pictures), on physiological considerations and on perceptions and beliefs in different external factors and causative agents linked with specific symptoms and ailments.

\section{Notes}

1 See e.g. Eisenberg (1977); Young (1982); Kleinman (1980); Kleinman and Good (1985); Kleinman (1988); Lock (1993); Tseng (2001); Garro (2002). See also E. Hsu's contribution and the introduction of this volume for discussion.

2 See e.g. Grmek (1989); Bleker and Brinkschulte (1995); Leven (1998, 2004) for critical perspectives of medical historians. See also Radestock (2015) for a recent analysis from the perspective of Egyptian medical papyri.

3 See e.g. Heeßel (2004a); Böck (2009) for critical viewpoints on retrospective diagnosis from the perspective of Mesopotamian medical texts. Cf. also recent studies on specific Mesopotamian disease terms or on groups of conditions, such as Wasserman (2012); Attia (2015); Beck (2015); Buisson (2016). 
4 See e.g. Heeßel (2004a: 5-6) for a critical appraisal. In medical anthropology, it has become conventional to differentiate between 'diseases' as defined by biomedicine and culture-specific 'illnesses' as described and elucidated through anthropological fieldwork (Kleinman 1980). 'Disease' in the biomedical sense refers to anatomical or physiological irregularities or abnormalities, while 'illness' refers to the 'culturally structured, personal experience of being unwell' (Sobo 2004: 3). Furthermore, the term 'sickness' as introduced by Allan Young (1982) highlights the social processes that shape the recognition of specific ailments within a given culture. With regard to Mesopotamian concepts and categories, the term 'disease' will be used in the present study in the sense of 'disorder', as a configuration of symptoms signifying an abnormal or impaired bodily, psychological or mental state diverging from a healthy condition. The disorders or 'diseases' in Mesopotamian medical texts should be viewed in the sense of 'appearances' (as conditions or bodily states having concrete characteristics that are understood as signs), a notion that can be compared with the phenomenological 'Gestalt of dis-ease' introduced by Elisabeth Hsu in her contribution in this book. The focus in the present chapter lies on elucidating Mesopotamian conceptualisations and categories from an emic point of view. For further discussion, see also the introduction to the present volume.

5 For surveys on Mesopotamian medicine, see e.g. Majno (1975); Biggs (1987-90); Scurlock and Andersen (2005); Attinger (2008); Robson (2008); Geller (2010); Fales (2016). For the healing practitioners as û and āšipu see e.g. Ritter (1965); Scurlock (1999); Jean (2006); Geller (2007); Attinger (2008: 71-7); Geller (2010: 43-88 and passim); Geller (2012); Steinert (2016); Fales (2018); Geller (2018); Steinert (2018).

6 Cf. Heeßel (2000: 79-96); Scurlock (2006); Steinert (2012); Böck (2014); Konstantopoulos (2017). See also Couto-Ferreira's contribution in this volume.

7 For diagnostic texts, see especially Heeßel (2000, 2010).

8 For an overview of Mesopotamian healing incantations and rituals see e.g. Collins (1999); Janowski and Wilhelm (2008: 1-15, 61-186); Schwemer (2011); Böck (2014: 77-128); overviews of the medical text sources can also be found in Geller (2010: 89-114); Scurlock (2014); Janowski and Schwemer (2010: 1-176). While both 'conjurers' and 'physicians' used healing spells in their practice, the genre of the prescription (bultu) seems to be intimately linked with the discipline of the 'physician'. The 'conjurers' specialised traditionally in various rituals related with health, well-being and the removal of any kind of evil or sickness, but their corpus and practice later also included other components such as medical recipes and drug handbooks.

9 For early Mesopotamian incantation literature see e.g. Cunningham (1997); George (2016). For early examples of medical prescriptions, see e.g. Wasserman (2007); Neumann (2010); Schwemer (2010).

10 For compendia of medical substances and drug lore see Powell (1993); SchusterBrandis (2008); Böck (2011); Stadhouders (2011, 2012); Böck (2015); Scurlock (2017, 277-80).

11 For Mesopotamian commentaries, see e.g. Frahm (2011); Geller (2010: 141-60).

12 With the exception of a few Sumerian texts from the end of the third millennium, the language of medical prescriptions is Akkadian (a Semitic language), and especially texts from the first millennium use many logograms as well as a specialised vocabulary betraying the technical nature of these texts. Incantations were composed in various languages: in Sumerian, Akkadian and other less well-known tongues such as Hurrian and Elamite.

13 In some instances, the texts stem from the libraries of healing practitioners or scholars excavated in their houses; in other instances they come from palace or temple libraries. See e.g. Pedersén (1985-86, 1998); Clancier (2009); Maul (2010); Robson (2013).

14 For excerpts and students' tablets with medical material see e.g. Finkel (2000); Maul (2010); Geller (2010: 131-40); for amulet tablets see e.g. Heeßel (2014); Farber (2014: 29-34 (Lamaštu amulets)). 
15 For the differentiation between collections and extracts/excerpts cf. Steinert (2015: 123).

16 For the concept of canonisation in Mesopotamian scholarly literature, see lately Worthington (2011); Koch (2015: 52-4); Rochberg (2016a); Steinert (2018).

17 For the casuistic structure of medical (and omen) texts, which was borrowed from juridical texts (e.g. laws), see Johnson (2015: 295-300).

18 For the diagnostic texts, including the Diagnostic Handbook Sakikkû (lit. 'sick strings' or 'symptoms'), see e.g. Labat (1951); Heeßel (2000: 47-68) discussing the structure of diagnostic entries. For the text of the Diagnostic Handbook see also Scurlock (2014: 13-271). Note the occasional warning in this text that the patient is in a critical state and that the healer should not 'approach/come close' to the patient (Heeßel (2000: 60-1).

19 See Heeßel (2000: 58-60). Both diagnostic and therapeutic texts are usually formulated taking a male patient and his body as a generalised model. Only the last section of the Diagnostic Handbook deals with women's bodies and their specific conditions (Tablets 36-39) and with paediatrics (Tablet 40). Geriatric problems are only dealt with rarely within the medical texts in general, although the age of the patient is occasionally taken into consideration (cf. Heeßel 2000: 42-3).

20 The translations of the cited texts are by the author, if not stated otherwise.

21 For the structure and vocabulary of medical prescriptions, see e.g. Goltz (1972); Geller (2010: 97-108). For textual examples see also CAD L 114-15 s.v. lazāzu and lazzu; CAD M/2 225 sub 1b; CAD Q 249 s.v. qību sub 4.

22 For efficacy phrases in Mesopotamian texts, see Steinert (2015); cf. Hsu's contribution in this volume concerned with Chinese medical manuscripts from the Yuan and Song period which feature similar phrases.

23 Translation after ETCSL text 1.1.1 Lines 11-28; cf. Attinger (1984: 6-9 lines 13-30); cf. Attinger (2011).

24 See Lambert and Millard (1969: 102-3); Foster (2005: 253) Tablet III vii 1-5 (Old Babylonian version): 'Now then, let there be a third (woman) among the people. Among the people are the woman who has given birth and the woman who has not given birth. Let there be (also) among the people the Pāšittu-demoness (lit. 'The one who wipes out'). Let her snatch the baby from the lap of the one who gave birth to it'. The next lines (6-9) refer to the installation of 'tabooed' women who are devoted to a deity and forbidden to bear children, as a further measure to cut down births among humans. For the baby-snatching demoness Lamaštu, see also Farber (2014) with further literature.

25 Compare further the Sumerian myth Enki and Ninmah, in which the two deities hold a competition to decide whose capacity to determine an anomalous being's destiny (i.e. to assign to it a social function) is paramount. In this competition, Enki manages to assign a fate to several human beings with physical impairments created by Ninmah (e.g. a blind man, a man who cannot bend his extremities, a woman who cannot give birth, a man with neither penis nor vagina), but the mother goddess Ninmah is unable to assign a lot to the being created by Enki which has multiple deformities and is 'neither dead nor alive'. See Benito (1969; ETCSL text 1.1.2).

26 The 'Belly Plant' spell was very popular in the Old Babylonian period, since it is attested in several copies and varying versions, and it continued to be used and transmitted to the first millennium texts. For discussion see e.g. Veldhuis $(1990,1993)$; Collins (1999: 137-51 and passim); George (2016: 129-32, 138 and passim). For the context and history of the belly incantations cf. also Steinert and Vacín (2018).

27 For discussion see Veldhuis (1990: 28-9, 42-3, 1993: 51-2); Collins (1999: 142-5); SEAL text 5.1.12.2.

28 For Mesopotamian demons, see e.g. Verderame (2011); Geller (2016); Verderame (2017).

29 Collins (1999: 262-5 'Teeth 1' lines 1-6 CT 17, 50: 1-6 and duplicates); Foster (2005: 995); for discussion see also Veldhuis (1990, 1993). 
30 This differentiation was introduced by G. Foster (1976) in a study of disease aetiologies encountered in non-Western medical systems.

31 Thus, Mesopotamian aetiologies could also be analysed in terms of A. Young's (1976) differentiation between 'internalising' and 'externalising' medical systems, as a medical tradition using both kinds of explanations. Cf. also the introduction to this volume for discussion.

32 See e.g. Heeßel (2000: 47-57); Couto-Ferreira (2007); Salin (2015). For the conceptualisation of sickness and aetiologies in Mesopotamian medical texts see also Attinger (2008: 60-8); Steinert (2012: 526-32); Fales (2016: 8-20); Steinert (2016: 211-19).

33 Cf. Scurlock and Andersen (2005: 429-528).

34 See Stol (1991-92: 45); Heeßel (2000: 49-52) noting that in contrast to the Diagnostic Handbook, the therapeutic texts feature fewer 'Hands' of specific deities, which are furthermore written in the form of logograms pointing to frozen technical expressions, while specific disease names and designations are more prominent in therapeutic texts than in the Diagnostic Handbook; cf. later for such designations.

35 It is not certain which inner organ is referred to by the 'pouch of the belly' (takalti libbi); neither can we be sure whether this expression is synonymous with takaltu 'bag', which may stand for different organs depending on the context, e.g. stomach and liver (cf. CAD T 61-3; Scurlock and Andersen 2005: 138 and passim; Steinert 2016: 207-9).

36 For the 'curse' inflicted as punishment for a broken oath and for witchcraft-related conditions see e.g. Maul (2004); Schwemer (2007); Abusch and Schwemer (2011, 2016); Maul 2019. For ghost-induced ailments see Scurlock (2006). For the 'Hand of the god/goddess', which is associated for example with mental and neurological conditions, see e.g. Stol (1993: 33-8); Abusch (1999); Scurlock and Andersen (2005: 439, 480-2).

37 For the link of Ištar with venereal conditions attributed to (illicit) sexual intercourse, see e.g. Diagnostic Handbook Tablet 22: 14-15 cited earlier, and for conditions caused by Lamaštu see Scurlock and Andersen (2005: 483-5 and passim); Farber (2007).

38 For demons and disease in Mesopotamian texts, see e.g. the collected papers in Verderame (2011), the surveys and collected materials in Stol (1993); Farber (2007); Scurlock and Andersen (2005: 429-528); Geller (2016); Verderame (2017).

39 For the history of the humours in Graeco-Roman medicine and later times see e.g. Arikha (2008). For the five phases/agents in Chinese medicine, see e.g. Hsu (2007).

40 For discussion of naturalistic (impersonal) aetiologies in Mesopotamian texts, see e.g. Scurlock and Andersen (2005: 18-24); Attinger (2008: 63-4); Steinert (2016: 211-22, 230-42).

41 For a study of these constructions with body parts as active agents and of the Akkadian verbs used in these contexts, e.g. 'to seize', 'to touch', 'to strike/hit', 'to fall on (the patient)', 'to overcome', see Salin (2015); cf. also Couto-Ferreira (2007: 12-19).

42 For examples of incantation rubrics referring to sick organs or body fluids (bile) and for healing spells addressing them as personalised beings, see Collins (1999: 152-64, 185-98, 214-19, 230-3 and passim); Böck (2014: 122-4).

43 The word pāšittu refers to a female demon associated with the child-snatcher Lamaštu as well as to an ailment. In medical commentaries and incantations, pāšittu is equated with the gallbladder and gall fluid (martu), but it is also associated with severe pain, as the logogram ZÚ.MUŠ.İ.GU $7 . E$ 'hurting (like) a snake bite' indicates; see CAD P 256-7; Scurlock and Andersen (2005: 137); Collins (1999: 231-2); Böck (2014: 123).

44 For a discussion of environmental influences, ranging from hazards such as spoiled water, parasites (e.g. worms), animals (e.g. scorpions, snakes), injuries, contagion and epidemics, the latter of which are often regarded as inflicted by a deity, see e.g. 
Scurlock and Andersen (2005: 13-25); Geller (2010: 68-9, 143-4); Fales (2016: 11-12); for seasonal illnesses see Steinert (2016: 217-18).

45 For șêtu-fever and fevers in Mesopotamian medicine in general, see also Cadelli (2000); Stol (2007); Bácskay (2017).

46 Cf. Bácskay (2017: 46-7).

47 For spells addressing wind that has caused an ailment (e.g. gastrointestinal or skin complaints), see e.g. Collins (1999: 77-80, 124-7, 134-7, 166-8); Scurlock and Andersen (2005: sub 'wind' and 'wind blasting'); for ghosts as winds, see e.g. Scurlock (2006: 58-9, 307: 13, 18, 345, 347: 33 and passim); cf. Steinert (2012: 322 with n. 103). Note also the group of the 'wind demons' (lilû, lilìtu, ardat lilî) which include the ghosts of adolescent girls and boys who died before marriage, which are connected with specific complaints such as psychiatric/neurological disorders and types of fever (see e.g. Stol 1993: 46-9; Scurlock and Andersen 2005: 95-6, 272-4, 337-8, 434-5, 444-5).

48 A similar idea of contracting illness (in this case a condition of the lower extremities) is through stepping into dirty wash water (see Eypper 2016: 2, 11, 13).

49 For this diagnosis, see also Diagnostic Handbook Tablet 12: 8; Tablet 17: 21-22, 64-66; cf. Tablet 11: 21; Tablet 26: 42; Tablet 27: 24-25 referring to the lurker-demon of the river attacking the victim while bathing.

$50 \mathrm{Cf}$. for instance designations such as șibit/li'bi šadî 'seizure of/li' bu-fever of the mountain (lands)' (Scurlock 2014: 678 (AMT 53/7+K 6732: 1-9); Stol 2007: 12-15), or references to the river or the steppe as places where one can be attacked by wild animals, enemies and sickness demons (e.g. Diagnostic Handbook Tablet 3: 32b, 109-113, 115-119; Tablet 9: 62, 79 referring to attacks in the steppe).

51 See e.g. Collins (1999); Böck (2014); Steinert (2016: 220-5, 2017a); Wee (2017).

52 For similar incantations drawing on environmental and technological imagery, see e.g. Collins (1999); Böck (2014: 101-6, 119-28); Steinert (2013, 2016: 223-5, 2017a).

53 CAD U/W 212-13; Scurlock and Andersen (2005: 82-3).

54 See e.g. Bácskay $(2017: 44,49)$.

55 The usage of the Akkadian term murșu 'sickness, disease' underscores this point (see CAD M/2 224-7). Thus, murșu occurs not only in connection with specific ailments or types of medical conditions, but is also encountered in passages or contexts that associate or group the term with words signifying debility or impairment, personal suffering and distress, social problems or misfortune. Moreover, murșu can be associated with general evil or with moral/religious terms such as 'wrongdoing', 'guilt', 'sin', 'punishment', broken taboos, but also with words related to concepts of pollution and infection (see e.g. van der Toorn 1985; Steinert 2012: 28-47; Feder 2016). Cf. also Couto-Ferreira's contribution in this volume.

56 See Geller (2005). Scurlock and Andersen (2005: 150-3) underline that the Mesopotamian healers employ this term 'to define a particular syndrome'. According to them, the category DÚR.GIG included conditions of the urethra and anus that involved a 'blocked or retarded passage of urine or stool'. Another example is murus kabbarti 'sickness of the ankle', which refers to a rather specific condition of the lower extremities, whose characteristic symptoms and development are described in the texts; see Eypper (2016) for discussion.

57 For these terms, see Schwemer (2007: 14-16, 63-4 and passim); Abusch and Schwemer (2011: 3-4, texts 10.1-10.5 and 12.1, 2016: text 10.6-10.18); Kinnier Wilson and Reynolds (2007: 72-6); Schwemer (2019).

58 For discussion of the term šiknu 'appearance' in connection with Mesopotamian descriptions and classifications of different phenomena, see the introduction to this volume.

59 Diagnostic Handbook Tablet 33: 23-24 (Heeßel 2000: 354, 360; Scurlock 2014: 232, 236). The word is probably related to sāmu 'red'. For sāmānu as an infectious skin 
condition affecting humans and a discussion of different attempts to identify this disorder with a biomedical condition, see Beck (2015). It is likely that the symptomologies linked with sāmānu correspond to several biomedical 'diseases', since it can befall humans and animals as well as plants; cf. CAD S 111-12.

60 Diagnostic Handbook Tablet 33: 28, 30; see also the entry in lines 29-31 (Heeßel 2000: 354, 360; Scurlock 2014: 232, 237) giving partially varying and overlapping symptoms. In line 31 , the condition is equated with the 'touch of the gods Marduk and/or Ninurta'; in lines 105b and 106b šadânu receives the limited attributions to 'Hand of Gula' and 'Hand of Ninurta' (cf. Böck 2014: 61-3, 73-4).

61 Diagnostic Handbook Tablet 33: 13 (Heeßel 2000: 353, 359; Scurlock 2014: 231, 236).

62 Sikkatu is described as an ailment in Tablet 33: 63 of the Diagnostic Handbook (Scurlock 2014: 233, 238), but in therapeutic texts, the occurrence of sikkatu-lesions of various colours on the patient's body is more often mentioned as a symptom (see e.g. Scurlock and Andersen 2005: 235-6). Sikkatu is also described as an infectious condition befalling domestic animals. It is thus likely that sikkatu is linked to multiple diseases (in the biomedical sense) depending on the context.

63 Diagnostic Handbook Tablet 33: 10 (Heeßel 2000: 353, 359; Scurlock 2014: 231, 236). Tablet 33: 111 equates ekkêtu with the 'Hand of (the sun-god) Šamaš' (Heeßel 2000: 358; Scurlock 2014: 235). Elsewhere in medical texts, ekketu is associated with itchiness and scratching of the skin and has been connected with scabies.

64 Diagnostic Handbook Tablet 33: 2, 5; see also 1, 3-4 and 6 with varying symptom descriptions. Line 6 describes a sub-type of the condition called 'fleeting aš $\hat{u}$ ', which is compared with louse bites and appears on the entire body. Line 103 equates $a \check{s} \hat{u}$ with the 'Hand of Gula' (see Heeßel 2000: 353, 357, 359; Scurlock 2014: 231, 235-6, 240).

65 Earlier, we encountered išătu as a term for fever, but in some texts, it refers to a red and painful skin condition (an abscess, rash or inflammation); see e.g. Scurlock and Andersen (2005: 239).

66 Another example for sub-types of the same condition are the 'male/female lamsatusore' (see BAM 580 iii 15' - 17', 20' - 22', discussed in Steinert 2016: 216-17; cf. later).

67 Diagnostic Handbook Tablet 33: 87; the second cited passage is from a therapeutic text (SpTU 1, 44: 29, 32). This word, bu'šānu, is an ailment (of both children and adults) affecting the mouth, nose or throat and characterised by a foul stench. Bu'šannu has been equated with diphtheria in Assyriological research, but the condition probably covers multiple biomedical 'diseases'; see Scurlock and Andersen (2005: 40-2) and Scurlock (2014: 389-98) for textual examples and discussion.

68 Diagnostic Handbook Tablet 33: 92 (Heeßel 2000: 357, 363, 371; Scurlock 2014: 234, 239), with parallel in BAM 578 iii 7.

69 Diagnostic Handbook Tablet 33: 93 (Heeßel 2000: 357, 363, 371; Scurlock 2014: 234, 239), with parallel in BAM 578 iv 26.

70 See Scurlock and Andersen (2005: 33-4, 141-2). Ahhāzu ( ${ }^{\mathrm{d} D I ̀ M . M E . L A G A B) ~}$ belongs to a group of demons associated with febrile conditions, including Labās $u$ ( ${ }^{\mathrm{d} D I M M . M E . A) ~ a n d ~ L a m a s ̌ t u ~(~}{ }^{\mathrm{d} D I ̀ M}$.ME). See CAD L 16-17; Scurlock and Andersen (2005: 686 n. 32), often also in diagnoses such as 'Hand of Ahhāzu/Labāṣu'. Cf. also Farber (2007); Bácskay (2017: 49-50) for Lamaštu and fever; George (2018) for discussion of the Sumerian pronounciation of ${ }^{\mathrm{d}}$ DìM.ME.

71 For amurriqānu see Scurlock and Andersen (2005: 138-9 and passim); cf. Böck (2014: 125-6) arguing that amurriqānu and ahhāzu are treated together with disorders of 'bile'/gallbladder in therapeutic compendia, and that the main difference between both was that amurriqānu was attributed to the healing goddess ('Hand of Gula'), while ahhāzu was linked with the 'Hand of Ninurta', Gula's consort (cf. Diagnostic Handbook Tablet 33: 107b; Böck 2014: 64-9, 74). However, the passages from 
the Diagnostic Handbook indicate that the healers reached these differing divine attributions on the basis of specific differentiated symptoms, which allowed them to make such fine-graded diagnoses.

72 See Stol (1993) for a detailed study of epilepsy and the various demons and divine agents linked with it.

73 See Heeßel (2000: 307-14 Tablet 28: 1, 7, 14, 17); Scurlock (2014: 211-13).

74 See BRM 4, 32 obv. 1-4; see Geller (2010: 168-76); Scurlock (2014: 339-46). The base text TCL 6, 34 i 1'-9' offers the same fumigation ritual for the case that either "AN.TA.ŠUB.BA, "Lord of the roof", "Hand of the god", "Hand of the goddess" or "Hand of a ghost" are upon a man'.

75 Cf. also Stol (1993: 8); see also Diagnostic Handbook Tablet 25: 15'-18' with the recurring symptom of drooling during epileptic fits or confusional states associated with AN.TA.ŠUB.BA.

76 See also Stol (1993: 16-17) with other diagnostic entries mentioning unusual movements of the eyes among the symptoms of 'Lord of the roof'.

77 Cf. Stol (1993: 33-6); Scurlock and Andersen (2005: 439); Steinert (2012: 394) for mental and neurological conditions associated with the 'Hand of the (personal) god'.

78 For 'heartbreak' (depression, melancholy) as a characteristic symptom of 'Hand of the goddess (Ištar)', see also Diagnostic Handbook Tablet 16: 154, Tablet 26: 28'29': 'If when (a confusional state) comes over him, his temples continually hurt him, his "heart" is continually breaking him (and) afterward he rubs his hands and feet, he rolls over and over, but he does not have any spittle, ..., (it is) miqtu (lit. "fall") (or) "Hand of Ištar"' (Scurlock 2014: 197, 201). Elsewhere in the therapeutic texts, 'heartbreak' is linked to the wrath of the personal god; see aforementioned. Cf. also Stol (1993: 36-8) for epilepsy and symptoms of 'Hand of the goddess/Ištar'.

79 For the passage, see also Stol (1993: 25-6). For ringing ears as one of the characteristic symptoms of a ghost-attack, see Scurlock (2006: 14 and 5-20, passim) for problems assigned to ghosts, including mental and neurological disorders, pain and problems related to digestion. See also Diagnostic Handbook 26: 34'-35' for ringing ears in the context of seizures attributed to the 'Hand of a ghost'.

80 The list is an important tool to represent semantic fields in Mesopotamia, and lexical or thematic lists form a basic feature of cuneiform scholarship and scribal culture deeply connected to scribal education/curricula (throughout all periods of Mesopotamian history). Several lexical lists are attested for different classes of things: professions, animals, stones, plants, objects made of reeds, metals, wood, types of containers etc. For an overview of Mesopotamian lexicography see Veldhuis (2014).

81 See the edition of the Old Babylonian precursor and first millennium version of the list of diseases in Landsberger (1967: 77-102); cf. Cavigneaux (1980-83: 630). For lists of body part terms see e.g. Couto-Ferreira (2009), and also Couto-Ferreira (2017) for the ordering principle 'head to toe' to represent and structure information concerning bodies and personified beings in Mesopotamian texts, including literary texts, omens, medicine and in incantations. Cf. also Steinert (2012).

82 See e.g. Wasserman (2007); Abusch (2016: Tablet II 52-64, V 58-72); Böck (2007: Mušš 'u IVa and f, Va and d, VI, VIIa, VIIIk); Geller (2016: Udug-hul Tablet II 62-71, III 138-144, VI 55-63, XIII-XV 220-230, XVI 168-175); Bácskay (2017: 52) for an overview.

83 Wasserman (2007: 44-6). A comparison between lists of diseases and enumerations in the Old Babylonian incantations shows only limited examples of identical or similar sequences of entries (Wasserman 2007: 47-9 with Table 3), while there is a considerable correspondence between diseases enumerated in the incantations and those treated in Old Babylonian medical prescriptions (Wasserman 2007: 52-5). For parallels between the disease lists and other texts see also Landsberger (1967: 103-9).

84 The ratio between superhuman agents and other disease names varies somewhat from incantation to incantation and depends on the overall context of the composition. 
85 Note for instance sikkatum 'pox, pimple' (lit. 'peg'), išātum 'fever; inflammation', miqtum 'fall', ašûm, ekkētum 'itching', li' bum (an infectious disease with fever) and other terms for fever (e.g. di' $u$ ), which are also attested outside medical texts, e.g. in letters, hemerologies or law texts (cf. Landsberger 1967: 107-8; Livingstone 2013).

86 For this process, often designated as 'canonisation' or serialisation, see e.g. Worthington (2011); Koch (2015: 52-4); Rochberg (2016a).

87 For these catalogues see Finkel (1988); Schmidtchen (2018); Steinert et al. (2018). For the serialisation and edition of the Diagnostic Handbook by the scholar Esagilkīn-apli see also Heeßel (2000: 104-10). The designation Corpus of Therapeutic Prescriptions is used here to refer to the medical corpus registered in the Assur Medical Catalogue.

88 The first complete edition and comprehensive discussion of the Assur Medical Catalogue can be found in Steinert et al. (2018); for a partial edition see Scurlock (2014: 295-306). Heeßel (2010: 31-5) offers a brief overview of the serialised therapeutic texts from Nineveh and other cities.

89 For discussion see e.g. Stol (1991-92); Heeßel (2000: 17-40); Schmidtchen (2018) on the structure of the Diagnostic Handbook.

90 The sections on women are Diagnostic Handbook section VI (Tablets 36-39) and sections XXI-XXII (PREGNANCY and BIRTH) of the AMC; sections dealing with sexuality are found in Diagnostic Handbook section V (Tablet 34) and in sections XIX-XX (POTENCY and SEX) in AMC.

91 For discussion see Heeßel (2000: 33-5 commentaries to Tablets 26-35); Schmidtchen (2018). It is worth mentioning here that the Corpus of Therapeutic Prescriptions outlined in the Assur Medical Catalogue very likely represents (in its core) the professional text corpus of the physician (asû), while the Diagnostic Handbook belonged to the corpus of the 'conjurer' (āsipu). On the other hand, the occurrence in Part 2 of the Corpus of Therapeutic Prescriptions of ritual titles, incantation genres and divination types typical for the text corpus and professional profile of the āsipu may indicate transfers or overlaps of textual material between the corpora of āšipu and $a s \hat{u}$.

92 Tablets 28-31; see Heeßel (2000: 307-52); Schmidtchen (2018).

93 Heeßel (2000: 24-30); cf. Steinert et al. (2018) for the contents of the Nineveh Medical Compendium; note in particular the sections dealing with respiratory conditions, internal ailments (gastrointestinal) and renal and rectal diseases as well as sections dealing with the mouth/teeth, the eyes, ears and lower extremities. Other ordering schemata of diagnostic entries found in the Diagnostic Handbook concern the thematic grouping of several diagnostic entries according to direction (right - left), according to time periods or the age of the patient (e.g. complaints occurring on different times of the day/in different months or having varying durations or temporal patterns of recurrence) or according to colour (with a fixed sequence). It can be shown, however, that sometimes groups of entries are arranged according to the diagnosis or prognosis. Furthermore, contents can be grouped according to thematic keywords or phrases and through association (Heeßel 2000: 37-40).

94 This tablet differentiates between cases of 'Lord of the roof' and 'spawn of Sulpaea' that 'is born with the patient' and cases of these two epilepsy forms 'falling' on the patient at different stages in life, all meriting a different prognosis (positive, negative or ambivalent), which is to be overcome by a recommended therapy. Remarkably, the two cases of 'Lord of the roof' and 'spawn of Šlpaea' at the moment of birth must have been regarded as threateningly dangerous, because the new-born patient is to be killed in both cases to avert disaster from the 'house of his father'. Interestingly, the text provides two contrasting sets of characteristic symptoms to differentiate between congenital 'Lord of the roof' and 'spawn of Sulpaea': in the former case, the newborn cries, twists and gets rigid from the moment it was born, while in the latter case these symptoms are absent. In contrast to the preceding passages, the cases of AN.TA.ŠUB.BA 'falling' on the patient in different contexts also provide a diagnosis 
assigning these illness episodes to the 'Hand' of a deity. Cf. Kinnier Wilson (2007) for a differing reading.

95 See e.g. Bourguignon (1976); Crapanzano (1977); Lambek (1993); Clark (2001); Shaw (2001); Cohen (2007); cf. McCormick and Goff(1992) for a clinical perspective.

96 For the problematic category of 'mental illness' in Mesopotamian medicine cf. Couto-Ferreira's contribution in this volume. It has to be underlined that Mesopotamian medicine does not clearly divide pathologies into somatic and mental disorders, although a number of texts focus on problems of the 'mind' (têmu) such as states of confusion and insanity (cf. Steinert 2012: 385-94).

97 See Johnson (2014), identifying material for STOMACH Tablet 4 and comparing it with the manuscripts of Diagnostic Handbook Tablet 31, showing that both tablets drew partially on a similar pool of older texts of mixed diagnostic/therapeutic character. Cf. Heeßel (2000: 347-8); Bácskay (2018) (for texts concerned with fever).

98 See Steinert et al. (2018: 231 on AMC line 31 and passim) for discussion.

99 Cf. Steinert (2016) for discussion.

100 See Stol (1991-92: 63-4) for references; cf. later.

101 Cf. Heeßel (2000: 35) arguing that the conditions in Tablet 33 form a more or less complete list (or summary) of the technical disease names occurring throughout the Diagnostic Handbook as diagnoses. It is clear that the formulary 'If the appearance of the lesion . . .. . . . is its name' was used in texts assigned to both professions (āšipu and $a s \hat{u}$ ), and the use of this formulary in Tablet 33 does not prove an origin of the passage in the latter discipline, but the fact that many of the conditions included there are treated in the therapeutic texts and often occur in a similar order suggests at least some stimulus by the therapeutic material (cf. Stol 1991-92: 64-5; Heeßel 2000: 364-70 with parallels). Note further that the incipit of the section SKIN in Part 2 of AMC, although differing from that of Tablet 33, also began 'If (the appearance of) the lesion'; cf. Steinert et al. (2018: 244) on AMC line 59 and passim for discussion.

102 An example for the systematisation of treatments in the late periods is the creation of specific series collecting prescriptions and associated incantations of a specific treatment type applied for various purposes, e.g. the series $M u \check{s} \breve{s} u$ 'u 'Rubbing; Massage' and Qutāru 'Fumigation' (see e.g. Böck 2007).

103 The term 'systems of correspondence' or medicine of systematic correspondences is used by Porkert (1974) for the theoretical framework of the five phases/agents in Chinese medicine.

104 For the five phases in Chinese medicine, see e.g. Unschuld (2003: 99-112 with Tables 1-7); Hsu (2007); Unschuld et al. (2011: Vol. 1, 91-3 and passim). For the history of the four humours see Arikha (2008).

105 For seasonal illness and influences in Mesopotamian medicine, see e.g. Steinert (2016: 217-19). For prognoses taking into account the seasonal development of an ailment, see e.g. Diagnostic Handbook Tablet 22: 69-72 (Heeßel 2000: 257; Scurlock 2014: 188, 192). For seasonal adjustments in the preparation of remedies (in the therapeutic texts), see e.g. Scurlock (2014: 363, 387-8, 453, 459, 476).

106 This polar correlation between right/left and male/female is well attested in Mesopotamia and beyond; see Stol $(1993: 33,36)$ with more examples. A similar group of entries can also be encountered in Tablet 14: 106-110, where divine agents punishing the patient with a 'disease of sexual intercourse' are listed in conjunction (Scurlock 2014: 131).

107 See BAM 112 ii 11'-12', Geller (2005: No. 4); Scurlock and Andersen (2005: 92 text 4.13): 'If a man's penis is 'blasted' by wind [and his penis] is covered with pustules'. Note also a similar correlation in col. ii 6'-7': 'If a man's penis is hot [. . .]: he is overcome by "sun-heat" (șetu)'.

108 See also BAM 584 ii 26, 29 for a variant association of Sîn with white pustules, and of Ištar with red pustules; cf. further Scurlock and Andersen (2005: 223-4 esp. texts 10.82-10.84, 454-5, 457-8 esp. text 19.105). 
109 See especially sections III and IV of the Diagnostic Handbook; note for an example from a therapeutic text Scurlock (2014: 387-8 (AMT 105/4 iv 7-20)), offering different prescriptions for ear problems depending on the month in which they occur.

110 See Heeßel (2000: 68 and discussion of Tablet 19/20: 88'-99'); Jean (2006); Livingstone (2013); Koch (2015: 212-33). Cf. also the next paragraph.

111 For Mesopotamian astrology and astral sciences see Koch-Westenholz (1995); Brown (2000); Rochberg (2004, 2010); Maul (2013: 237-95); Koch (2015: 146-212).

112 See the so-called Diviner's Manual (Oppenheim 1974: 203-5, 207 lines 22-4, 36-40, 53-6).

113 For Mesopotamian astro-magic and astro-medicine see e.g. Reiner (1995); Heeßel (2005, 2008); Geller (2014); Wee (2014, 2015); Steinert (2016: 225-30).

114 For similar texts correlating e.g. stars, constellations or zodiac signs with diseases or deities that cause them see e.g. Heeßel (2008).

115 For further examples with prescriptions based on the 'stone-wood-plant' scheme see Heeßel $(2005,2008)$.

116 For the text see Hunger (1976: 50-1); Heeßel (2010: 30-1); Geller (2014: 3-25); Steinert (2016: 230-42 with earlier literature).

117 See Steinert (2016: 234-5); Steinert (2017b: 50-64) for discussion and further literature. While libbu can refer to different organs (heart, stomach, belly, uterus) or vaguely to the inside of the body, in SpTU 1, 43, the word has to denote a concrete organ, and the 'beating heart' is known as the seat of emotions such as fear or anxiety. Cf. also Couto-Ferreira's contribution in this volume.

118 Cf. also Cadelli (2000); Stol (2006) for conditions of the respiratory organs attributed to the ingestion of bewitched food and for respiratory conditions 'turning into' ailments of the gastrointestinal system.

\section{References}

Abusch, T. (1999) 'Witchcraft and the Anger of the Personal God', in Abusch, T. and van der Toorn, K. (eds.) Mesopotamian Magic: Textual, Historical and Interpretative Perspectives. Groningen: Styx, 81-122.

Abusch, T. (2016) The Magical Ceremony Maqlû: A Critical Edition. Leiden/Boston: Brill. Abusch, T. and Schwemer, D. (2011) Corpus of Mesopotamian Anti-Witchcraft Rituals. Vol. 1. Leiden/Boston: Brill.

Abusch, T. and Schwemer, D. (with G. van Buylaere and M. Luukko) (2016) Corpus of Mesopotamian Anti-witchcraft Rituals. Vol. 2. Leiden/Boston: Brill.

Arikha, N. (2008) Passions and Tempers: A History of the Humours. New York: Harper Perennial.

Attia, A. (2015) 'Traduction et commentaires des trois premières tablettes de la série IGI', Le Journal des Médecines Cunéiformes 25, 1-120.

Attinger, P. (1984) 'Enki et Ninhursaĝa', Zeitschrift für Assyriologie und Vorderasiatische Archäologie 74, 1-52.

Attinger, P. (2008) 'La médecine mésopotamienne', Le Journal des Médecines Cunéiformes 11-12, 1-96.

Attinger, P. (2011 [2015]) 'Enki and Ninhursaĝa (1.1.1)' (www.iaw.unibe.ch/ueber_uns/ amm_amp_va_personen/prof_dr_attinger_pascal\#pane122850) (Accessed 7 December 2017).

Bácskay, A. (2017) 'The Natural and Supernatural Aspects of Fever in Mesopotamian Medical Texts', in Bhayro, S. and Rider, C. (eds.) Demons and Illness from Antiquity to the Early-Modern Period. Boston/Leiden: Brill, 39-52. 
Bácskay, A. (2018) Therapeutic Prescriptions against Fever in Ancient Mesopotamia. Münster: Ugarit-Verlag.

Beck, S. (2015) 'Sāmānu as a Human Disease', Le Journal des Médecines Cunéiformes 26, 33-46.

Benito, C. A. (1969) Enki and Ninmah and Enki and the World Order. PhD Dissertation, University of Pennsylvania. Ann Arbor: UMI.

Biggs, R. D. (1987-90) 'Medizin: A. In Mesopotamien', Reallexikon der Assyriologie und Vorderasiatischen Archäologie 7, 623-9.

Biggs, R. D. (1991) 'Ergotism and Other Mycotoxicoses in Ancient Mesopotamia?', in Michalowski, P. et al. (eds.) Velles Paraules: Ancient Near Eastern Studies in Honor of Miguel Civil on the Occasion of His Sixty-Fifth Birthday. Barcelona: Sabadell, 15-21.

Bleker, J. and Brinkschulte, E. (1995) 'Windpocken, Varioloiden oder echte Menschenpocken? - $\mathrm{Zu}$ den Fallstricken der retrospektiven Diagnose', NTM. Internationale Zeitschrift für Geschichte und Ethik der Naturwissenschaft, Technik und Medizin 3, 97-116.

Böck, B. (2007) Das Handbuch Muššu'u 'Einreibung': Eine Serie sumerischer und akkadischer Beschwörungen aus dem 1. Jt. vor Chr. Madrid: Consejo Superior de Investigaciones Científicas.

Böck, B. (2009) 'Diagnose im Alten Mesopotamien: Überlegungen zu Grenzen und Möglichkeiten der Interpretation keilschriftlicher diagnostischer Texte', Orientalistische Literaturzeitung 104, 381-98.

Böck, B. (2011) 'Sourcing, Organising and Administering Medical Ingredients', in Radner, K. and Robson, E. (eds.) The Oxford Handbook of Cuneiform Cultures. Oxford: Oxford University Press, 690-705.

Böck, B. (2014) The Healing Goddess Gula: Towards an Understanding of Ancient Babylonian Medicine. Leiden/Boston: Brill.

Böck, B. (2015) 'Shaping Texts and Text Genres: On the Drug Lore of Babylonian Practitioners of Medicine', Aula Orientalis 33, 21-37.

Bourguignon, E. (1976) Possession. San Francisco: Chandler and Sharp.

Brown, D. (2000) Mesopotamian Planetary Astronomy-Astrology. Groningen: Styx.

Buisson, G. (2016) 'À la recherche de la mélancolie en Mésopotamie ancienne', Le Journal des Médecines Cunéiformes 28, 1-54.

Cadelli, D. (2000) Recherche sur la médecine mésopotamienne. La série šumma amêlu suâlam marus. PhD Dissertation, Université de Paris I Panthéon Sorbonne.

Cavigneaux, A. (1980-83) 'Lexikalische Listen', Reallexikon der Assyriologie und Vorderasiatischen Archäologie 6, 609-41.

Civil, M. (1974) 'Medical Commentaries from Nippur', Journal of Near Eastern Studies 33, 329-38.

Clancier, F. (2009) Les bibliothèques en Babylonie dans la deuxième moitié du Ier millénaire av. J.-C. Münster: Ugarit-Verlag.

Clark, S. (2001) 'Possession', in Blakemore, C. and Jennet, S. (eds.) The Oxford Companion to the Body. Oxford: Oxford University Press, 551-2.

Cohen, E. E. A. (2007) The Mind Possessed: The Cognition of Spirit Possession in AfroBrazilian Religious Tradition. Oxford: Oxford University Press.

Collins, T. J. (1999) Natural Illness in Babylonian Medical Incantations. PhD Dissertation, University of Chicago. Ann Arbor: UMI.

Couto-Ferreira, M. E. (2007) 'Conceptos de transmisión de la enfermedad en Mesopotamia: algunas reflexiones', Historiae 4, 1-23. 
Couto-Ferreira, M. E. (2009) Etnoanatomía y partonomía del cuerpo humano en sumerio y acadio. El léxico Ugu-mu. PhD Dissertation. Barcelona: Universitat Pompeu Fabra.

Couto-Ferreira, M. E. (2017) 'From Head to Toe: Listing the Body in Cuneiform Texts', in Wee, J. Z. (ed.) The Comparable Body: Analogy and Metaphor in Ancient Mesopotamian, Egyptian, and Greco-Roman Medicine. Leiden/Boston: Brill, 43-71.

Crapanzano, V. (ed.) (1977) Case Studies in Spirit Possession. New York: Wiley.

Cunningham, G. (1997) 'Deliver Me from Evil': Mesopotamian Incantations 2500-1500 $B C$. Rome: Editrice Pontificio Istituto Biblico.

Eisenberg, L. (1977) 'Disease and Illness: Distinctions between Professional and Popular Ideas of Sickness', Culture, Medicine and Psychiatry 1, 9-23.

Eypper, S. C. (2016) 'Diseases of the Feet in Babylonian-Assyrian Medicine: A Study of Text K.67+', Le Journal des Médecines Cunéiformes 27, 1-58.

Fales, F. M. (2016) 'Anatomy and Surgery in Ancient Mesopotamia: A Bird's-Eye View', in Perdicoyianni-Paléologou, H. (ed.) Anatomy and Surgery from Antiquity to the Renaissance. Amsterdam: Adolf M. Hakkert Editore, 3-71.

Fales, F. M. (ed.) (2018) La medicina assiro-babilonese. Con la collaborazione di Francesca Minen. Roma: Scienze e lettere.

Farber, W. (2007) 'Lamaštu: Agent of a Specific Disease or a General Destroyer of Health?', in Finkel, I. L. and Geller, M. J. (eds.) Disease in Babylonia. Leiden/Boston: Brill, 137-45.

Farber, W. (2014) Lamaštu: An Edition of the Canonical Series of Lamaštu Incantations and Rituals and Related Texts from the Second and First Millennia B.C. Winona Lake: Eisenbrauns.

Feder, Y. (2016) 'Defilement, Disgust, and Disease: The Experiential Basis of Hittite and Akkadian Terms for Impurity', Journal of the American Oriental Society 136, 99-116.

Finkel, I. L. (1988) 'Adad-apla-iddina, Esagil-kīn-apli, and the Series SA.GIG', in Leichty, E., de Jong Ellis, M. and Gerardi, P. (eds.) A Scientific Humanist: Studies in Memory of Abraham Sachs. Occasional Publications of the Samuel Noah Kramer Fund 9. Philadelphia: University Museum, 143-59.

Finkel, I. L. (2000) 'On Late Babylonian Medical Training', in George, A. R. and Finkel, I. L. (eds.) Wisdom, Gods and Literature: Studies in Assyriology in Honour of W.G. Lambert. Winona Lake: Eisenbrauns, 137-223.

Foster, B. R. (1996) Before the Muses: An Anthology of Akkadian Literature. Second edition. Bethesda: CDL Press.

Foster, B. R. (2005) Before the Muses: An Anthology of Akkadian Literature. Third edition. Bethesda: CDL Press.

Foster, G. (1976) 'Disease Etiologies in Non-Western Medical Systems', American Anthropologist 78, 773-82.

Frahm, E. (2011) Babylonian and Assyrian Commentaries: Origins of Interpretation. Münster: Ugarit-Verlag.

Garro, L. C. (2002) 'Hallowell's Challenge: Explanations of Illness and Cross-Cultural Research', Anthropological Theory 2, 77-97.

Geller, M. J. (2005) Renal and Rectal Diseases. Berlin/New York: de Gruyter.

Geller, M. J. (2007) 'Médecine et magie: l'aŝu, l'âšipu et le mašmâšs', Le Journal des Médecines Cunéiformes 9, 1-15.

Geller, M. J. (2010) Ancient Babylonian Medicine: Theory and Practice. Chichester: Wiley-Blackwell.

Geller, M. J. (2012) 'Y a-t-il une magie sans médecine en Mésopotamie?', Le Journal des Médecines Cunéiformes 20, 43-52. 
Geller, M. J. (2014) Melothesia in Babylonia: Medicine, Magic, and Astrology in the Ancient Near East. Boston: de Gruyter.

Geller, M. J. (2016) Healing Magic and Evil Demons: Canonical Udug-hul Incantations. Boston/Berlin: de Gruyter.

Geller, M. J. (2018) 'Babylonian Medicine as a Discipline', in Jones, A. and Taub, L. (eds.) The Cambridge History of Science, Volume 1: Ancient Science. Cambridge: Cambridge University Press, 29-57.

Geller, M. J. and Cohen, S. L. (1995) 'Kidney and Urinary Tract Disease in Ancient Babylonia, with Translations of the Cuneiform Sources', Kidney International 47, 1811-15.

George, A. R. (1991) 'Babylonian Texts from the Folios of Sidney Smith, Part Two: Prognostic and Diagnostic Omens', Revue d'Assyriologie 85, 137-65.

George, A. R. (2016) Mesopotamian Incantations and Related Texts in the Schøyen Collection. Bethesda: CDL Press.

George, A. R. (2018) 'Kamadme, the Sumerian Counterpart of the Demon Lamaštu', in van Buylaere, G., Luukko, M. and Mertens-Wagschal, A. (eds.) Sources of Evil: Studies in Mesopotamian Exorcistic Lore. Boston/Leiden: Brill, 150-7.

Goltz, D. (1972) Studien zur altorientalischen und griechischen Heilkunde: Therapie Arzneibereitung - Rezeptstruktur. Wiesbaden: Franz Steiner Verlag.

Grmek, M. D. (1989) Disease in the Ancient Greek World. Baltimore/London: John Hopkins University Press.

Haussperger, M. (2012) Die mesopotamische Medizin aus ärztlicher Sicht. Baden-Baden: Deutscher Wissenschafts-Verlag.

Heeßel, N. P. (2000) Babylonisch-assyrische Diagnostik. Münster: Ugarit-Verlag.

Heeßel, N. P. (2004a) 'Reading and Interpreting Medical Cuneiform Texts: Methods and Problems', Le Journal des Médecines Cunéiformes 3, 2-9.

Heeßel, N. P. (2004b) 'Diagnosis, Divination and Disease: Towards an Understanding of the Rationale behind the Babylonian Diagnostic Handbook', in Horstmannshoff, H. and Stol, M. (eds.) Magic and Rationality in Ancient Near Eastern and Graeco-Roman Medicine. Leiden: Brill, 97-116.

Heeßel, N. P. (2005) 'Stein, Pflanze und Holz: Ein neuer Text zur "medizinischen Astrologie"', Orientalia Nova Series 71, 1-22.

Heeßel, N. P. (2008) 'Astrological Medicine in Babylonia', in Akasoy, A., Burnett, C. and Yoeli-Tlalim, R. (eds.) Astro-Medicine: Astrology and Medicine, East and West. Florence: SISMEL-Edizioni del Galluzzo, 1-16.

Heeßel, N. P. (2010) 'Diagnostische Texte', in Janowski, B. and Schwemer, D. (eds.) Texte aus der Umwelt des Alten Testaments, Neue Folge Band 5. Texte zur Heilkunde. Gütersloh: Gütersloher Verlagshaus, 8-31.

Heeßel, N. P. (2014) “Amulette und “Amulettform”: Zum Zusammenhang von Form, Funktion, und Text von Amuletten im Alten Mesopotamien', in Quack, J. F. and Luft, D. C. (eds.) Erscheinungsformen und Handhabung heiliger Schriften. Berlin: de Gruyter, 55-79.

Hsu, E. (2007) 'The Biological in the Cultural: The Five Agents and the Body Ecologic in Chinese Medicine', in Parkin, D. and Ulijaszek, S. (eds.) Holistic Anthropology: Emergence and Convergence. Oxford: Berghahn, 91-126.

Hunger, H. (1976) Spätbabylonische Texte aus Uruk. Teil I. Berlin: Gebr. Mann Verlag.

Janowski, B. and Schwemer, D. (eds.) (2010) Texte aus der Umwelt des Alten Testaments, Neue Folge Band 5. Texte zur Heilkunde. Gütersloh: Gütersloher Verlagshaus.

Janowski, B. and Wilhelm, G. (eds.) (2008) Texte aus der Umwelt des Alten Testaments, Neue Folge Band 4. Omina, Orakel, Rituale und Beschwörungen. Gütersloh: Gütersloher Verlagshaus. 
Jean, C. (2006) La magie néo-assyrienne en contexte. Recherches sur le métier d'exorciste et le concept d'āšipūtu. State Archives of Assyria Studies 17. Helsinki: The Neo-Assyrian Text Corpus Project.

Johnson, J. C. (2014) 'Towards a Reconstruction of SUALU IV: Can We Localize K 2386+ in the Therapeutic Corpus?', Le Journal des Médecines Cunéiformes 24, 11-38.

Johnson, J. C. (2015) 'Depersonalized Case Histories in the Babylonian Therapeutic Compendia', in Johnson, J. C. (ed.) In the Wake of the Compendia: Infrastructural Contexts and the Licensing of Empiricism in Ancient and Medieval Mesopotamia. Boston/Berlin: de Gruyter, 289-315.

Kinnier Wilson, J. V. (1994) 'The samānu Disease in Babylonian Medicine', Journal of Near Eastern Studies 53, 111-15.

Kinnier Wilson, J. V. (2007) 'Infantile and Childhood Convulsions and SA.GIG XXIX', in Finkel, I. L. and Geller, M. J. (eds.) Disease in Babylonia. Leiden/Boston: Brill, 62-6.

Kinnier Wilson J. V. and Reynolds, E. H. (2007) 'On Stroke and Facial Palsy in Babylonian Texts', in Finkel, I. L. and Geller, M. J. (eds.) Disease in Babylonia. Leiden/Boston: Brill, 67-99.

Kleinman, A. (1980) Patients and Healers in the Context of Culture: An Exploration of the Borderland between Anthropology, Medicine, and Psychiatry. Berkeley: University of California Press.

Kleinman, A. (1988) Rethinking Psychiatry: From Cultural Category to Personal Experience. New York: Free Press.

Kleinman, A. and Good, B. (1985) Culture and Depression: Studies in the Anthropology and Cross-Cultural Psychiatry of Affect and Disorder. Berkeley: University of California Press.

Koch, U. S. (2015) Mesopotamian Divination Texts: Conversing with the Gods: Sources from the First Millennium BCE. Münster: Ugarit-Verlag.

Köcher, F. (1986) 'Saharšubbû - Zur Frage nach der Lepra im alten Zweistromland', in Wolf, J. H. (ed.) Aussatz - Lepra - Hansen-Krankheit: Ein Menschheitsproblem im Wandel. Teil 2: Aufsätze. Würzburg: Deutsches Medizinhistorisches Museum, 27-34.

Koch-Westenholz, U. S. (1995) Mesopotamian Astrology: An Introduction to Babylonian and Assyrian Celestial Divination. Copenhagen: Carsten Niebuhr Institute of Near Eastern Studies/Museum Tusculanum Press.

Konstantopoulos, G. (2017) 'Shifting Alignments: The Dichotomy of Benevolent and Malevolent Demons in Mesopotamia', in Bhayro, S. and Rider, C. (eds.) Demons and Illness from Antiquity to the Early-Modern Period. Boston/Leiden: Brill, 19-38.

Labat, R. (1951) Traité akkadien de diagnostics et prognostics médicaux. Paris: Academie Internationale d'Histoire des Sciences/Leiden: Brill.

Lambek, M. (1993) Knowledge and Practice in Mayotte: Local Discourses of Islam, Sorcery and Spirit Possession. Toronto: University of Toronto Press.

Lambert, W. G. (1970) 'Fire Incantations', Archiv für Orientforschung 23, 39-45 and Pl. I-XI.

Lambert, W. G. and Millard, A. R. (1969) Atra-hasis: The Babylonian Story of the Flood. Oxford: Clarendon.

Landsberger, B. (1967) HAR-ra = hubullu Tablet XV and Related Texts. Rome: Pontificium Institutum Biblicum.

Leven, K.-H. (1998) 'Krankheiten - historische Deutung versus retrospektive Diagnose', in Paul, N. and Schlich, T. (eds.) Medizingeschichte: Aufgaben - Probleme - Perspektiven. Frankfurt a. M.: Campus, 153-85.

Leven, K.-H. (2004) 'At Times These Ancient Facts Seem to Lie before Me Like a Patient on a Hospital Bed: Retrospective Diagnosis and Ancient Medical History', in 
Horstmanshoff, H. F. J. and Stol, M. (eds.) Magic and Rationality in Ancient Near Eastern and Graeco-Roman Medicine. Leiden/Boston: Brill, 369-86.

Littlewood, R. (ed.) (2007) On Knowing and Not Knowing in the Anthropology of Medicine. Walnut Creek: Left Coast Press.

Livingstone, A. (2013) Hemerologies of Assyrian and Babylonian Scholars. Bethesda: CDL Press.

Lock, M. (1993) Encounters with Aging: Mythologies of Menopause in Japan and North America. Berkeley: University of California Press.

Majno, G. (1975) The Healing Hand: Man and Wound in the Ancient World. Cambridge: Harvard University Press.

Maul, S. M. (2004) 'Die "Lösung vom Bann": Überlegungen zu altorientalischen Konzeptionen von Krankheit und Heilkunst', in Horstmanshoff, H. F. J. and Stol, M. (eds.) Magic and Rationality in Ancient Near Eastern and Graeco-Roman Medicine. Leiden/ Boston: Brill, 79-95.

Maul, S. M. (2010) 'Die Tontafelbibliothek aus dem sogenannten "Haus des Beschwörungspriesters"', in Maul, S. M. and Heeßel, N. P. (eds.) Assur-Forschungen: Arbeiten aus der Forschungsstelle "Edition literarischer Keilschrifttexte aus Assur" der Heidelberger Akademie der Wissenschaften. Wiesbaden: Harrassowitz-Verlag, 189-228.

Maul, S. M. (2013) Die Wahrsagekunst im Alten Orient: Zeichen des Himmels und der Erde. München: C. H. Beck.

Maul, S. M. (2019) Bannlösung (nam-érim-búr-ru-da): Die Therapie eines auf eidliche Falschaussage zurückgeführten Leidens. Wiesbaden: Harrassowitz.

McCormick, S. and Goff, D. C. (1992) 'Possession States: Approaches to Clinical Evaluation and Classification', Behavioural Neurology 5, 161-7.

Neumann, H. (2010) 'Texte des 3. Jt. v. Chr.', in Janowski, B. and Schwemer, D. (eds.) Texte aus der Umwelt des Alten Testaments, Neue Folge Band 5, Texte zur Heilkunde. Gütersloh: Gütersloher Verlagshaus, 3-7.

Olivier de Sardan, J.-P. (1998) 'Illness Entities in West Africa', Anthropology and Medicine 5, 193-217.

Olivier de Sardan, J.-P. (1999) 'Les representations des maladies: des modules?', in Jaffré, J. and Olivier de Sardan, J.-P. (eds.) La construction sociale des maladies: Les entités nosologiques populaires en Afrique de l'Ouest. Paris: PUF, 15-40.

Oppenheim, A. L. (1974) ‘A Babylonian Diviner's Manual', Journal of Near Eastern Studies 33, 197-220.

Parys, M. (2014) 'Édition d'un texte médical thérapeutique retrouvé à Assur (BAM 159)', Le Journal des Médecines Cunéiformes 23, 1-88.

Pedersén, O. (1985-86) Archives and Libraries in the City of Assur: A Survey of the Material from the German Excavations. 2 Vol. Uppsala: Almqvist and Wiksell.

Pedersén, O. (1998) Archives and Libraries in the Ancient Near East, 1500-300 B.C. Bethesda: CDL Press.

Porkert, P. (1974) The Foundations of Chinese Medicine: Systems of Correspondence. Cambridge, MA: MIT Press.

Powell, M. A. (1993) 'Drugs and Pharmaceuticals in Ancient Mesopotamia', in Jacob, I. and Jacob, W. (eds.) The Healing Past: Pharmaceuticals in the Biblical and Rabbinic World. Leiden: Brill, 47-68.

Radestock, S. (2015) Prinzipien der ägyptischen Medizin: Medizinische Lehrtexte der Papyri Ebers und Smith: Eine wissenschaftstheoretische Annäherung. Würzburg: Ergon. Reiner, E. (1995) Astral Magic in Babylonia. Transactions of the American Philosophical Society, New Series 85/4. Philadelphia: The American Philosophical Society. 
Ritter, E. (1965) 'Magical-Expert (= āšipu) and Physician (=asû): Notes on Two Complementary Professions in Babylonian Medicine', in Studies in Honor of Benno Landsberger on His Seventy-Fifth Birthday, April 21, 1965. Chicago: The University of Chicago Press, 299-321.

Robson, E. (2008) 'Mesopotamian Medicine and Religion: Current Debates, New Perspectives', Religion Compass 2(4), 455-83.

Robson, E. (2013) 'Reading the Libraries of Assyria and Babylonia', in König, J., Oikonomopolou, K. and Woolf, G. (eds.) Ancient Libraries. Cambridge: Cambridge University Press, 38-56.

Rochberg, F. (2004) The Heavenly Writing: Divination, Horoscopy and Astronomy in Mesopotamian Culture. Cambridge: Cambridge University Press.

Rochberg, F. (2010) In the Path of the Moon: Babylonian Celestial Divination and Its Legacy. Leiden: Brill.

Rochberg, F. (2016a) 'Canonicity and Power in Cuneiform Scribal Scholarship', in Ryholt, K. and Barjamovic, G. (eds.) Problems of Canonicity and Identity Formation in Ancient Egypt and Mesopotamia. Copenhagen: Museum Tusculanum Press, 217-29.

Rochberg, F. (2016b) Before Nature: Cuneiform Knowledge and the History of Science. Chicago/London: The University of Chicago Press.

Salin, S. (2015) "When Disease "Touches", "Hits", or "Seizes" in Assyro-Babylonian Medicine', KASKAL - Rivista di Storia, Ambienti e Culture del Vicino Oriente Antico 12, 319-36.

Schmidtchen, E. (2018) 'Esagil-kīn-apli's Catalogue of Sakikkû and Alamdimmû' and 'The

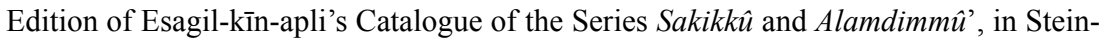
ert, U. (ed.) Assyrian and Babylonian Scholarly Text Catalogues: Medicine, Magic and Divination. Berlin: de Gruyter, 137-57 and 313-33.

Schuster-Brandis, A. (2008) Steine als Schutz- und Heilmittel: Untersuchung zu ihrer Verwendung in der Beschwörungskunst Mesopotamiens im 1. Jt. v. Chr. Münster: Ugarit-Verlag.

Schwemer, D. (2007) Abwehrzauber und Behexung: Studien zum Schadenzauberglauben im alten Mesopotamien. Wiesbaden: Harrassowitz.

Schwemer, D. (2010) 'Altbabylonische therapeutische Texte', in Janowski, B. and Schwemer, D. (eds.) Texte aus der Umwelt des Alten Testaments, Neue Folge Band 5, Texte zur Heilkunde. Gütersloh: Gütersloher Verlagshaus, 35-8.

Schwemer, D. (2011) 'Magic Rituals: Conceptualization and Performance', in Radner, K. and Robson, E. (eds.) The Oxford Handbook of Cuneiform Culture. Oxford: Oxford University Press, 419-41.

Schwemer, D. (2019) 'Mesopotamia', in Frankfurter, D. (ed.) Guide to the Study of Ancient Magic. Leiden/Boston: Brill, 36-64.

Scurlock, J. (1999) 'Physician, Exorcist, Conjurer, Magician: A Tale of Two Healing Professionals', in Abusch, T. and van der Toorn, K. (eds.) Mesopotamian Magic: Textual, Historical, and Interpretative Perspectives. Groningen: Styx, 69-79.

Scurlock, J. (2006) Magico-Medical Means of Treating Ghost-Induced Illnesses in Ancient Mesopotamia. Leiden: Brill.

Scurlock, J. (2014) Sourcebook for Ancient Mesopotamian Medicine. Atlanta: SBL Press.

Scurlock, J. (2017) 'Medical Texts', in Lawson Younger, K., Jr. (ed.) The Context of Scripture, Volume 4: Supplements. Leiden/Boston: Brill, 277-312.

Scurlock, J. and Andersen, B. R. (2005) Diagnoses in Assyrian and Babylonian Medicine: Ancient Sources, Translations, and Modern Medical Analyses. Urbana/Chicago: University of Illinois Press. 
Shaw, J. (2001) 'Spirit Possession', in Blakemore, C. and Jennet, S. (eds.) The Oxford Companion to the Body. Oxford: Oxford University Press, 644.

Sobo, E. J. (2004) 'Theoretical and Applied Issues in Cross-Cultural Health Research', in Ember, C. R. and Ember, M. (eds.) Encyclopedia of Medical Anthropology: Health and Illness in the World's Cultures. Vol. 1: Topics. New York: Kluwer Academic/Plenum Publishers, 3-11.

Stadhouders, H. (2011) 'The Pharmacopoeial Handbook Šammu šikinšu: An Edition', Le Journal des Médecines Cunéiformes 18, 3-51.

Stadhouders, H. (2012) 'The Pharmacopoeial Handbook Šammu šikinšu: A Translation', Le Journal des Médecines Cunéiformes 19, 1-21.

Steinert, U. (2012) Aspekte des Menschseins im Alten Mesopotamien. Eine Studie zu Person und Identität im 2. und 1. Jt. v. Chr. Leiden/Boston: Brill.

Steinert, U. (2013) 'Fluids, Rivers, and Vessels: Metaphors and Body Concepts in Mesopotamian Gynaecological Texts', Le Journal des Médecines Cunéiformes 22, 1-23.

Steinert, U. (2015) 'Tested Remedies in Mesopotamian Medical Texts: A Label for Efficacy Based on Empirical Observation?', in Johnson, J. C. (ed.) In the Wake of the Compendia: Infrastructural Contexts and the Licensing of Empiricism in Ancient and Medieval Mesopotamia. Boston/Berlin: de Gruyter, 103-45.

Steinert, U. (2016) 'Körperwissen, Tradition und Innovation in der babylonischen Medizin', in Renger, A.-B. and Wulf, C. (eds.) Körperwissen: Transfer und Innovation. Paragrana. Internationale Zeitschrift für Historische Anthropologie 25/1. Berlin: de Gruyter, 195-254.

Steinert, U. (2017a) 'Concepts of the Female Body in Mesopotamian Gynecological Texts', in Wee, J. Z. (ed.) The Comparable Body: Analogy and Metaphor in Ancient Mesopotamian, Egyptian, and Greco-Roman Medicine. Leiden/Boston: Brill, 275-357.

Steinert, U. (2017b) 'Person, Identität und Individualität im antiken Mesopotamien', in Bons, E. and Finsterbusch, K. (eds.) Konstruktionen individueller und kollektiver Identität (II): Alter Orient, hellenistisches Judentum, römische Antike, Alte Kirche. Göttingen: Vandenhoeck \& Ruprecht, 39-100.

Steinert, U. (ed.) (2018) Assyrian and Babylonian Scholarly Text Catalogues: Medicine, Magic and Divination. Berlin: de Gruyter.

Steinert, U. and Vacín, L. (2018) 'BM 92518 and Old Babylonian Incantations for the "Belly", in Panayotov, S. V. and Vacín, L. (eds.) Mesopotamian Medicine and Magic: Studies in Honor of Markham J. Geller. Boston/Leiden: Brill, 694-740.

Steinert, U. et al. (2018) 'The Assur Medical Catalogue (AMC)', in Steinert, U. (ed.) Assyrian and Babylonian Scholarly Text Catalogues: Medicine, Magic and Divination. Berlin: de Gruyter, 203-91.

Stol, M. (1991-92) 'Diagnosis and Therapy in Babylonian Medicine', Jaarbericht "Ex Oriente Lux" 32, 42-65.

Stol, M. (1993) Epilepsy in Babylonia. Groningen: Styx.

Stol, M. (2000) Birth in Babylonia and the Bible: Its Mediterranean Setting. Groningen: Styx.

Stol, M. (2006) 'The Digestion of Food According to Babylonian Sources', in Battini, L. and Villard, P. (eds.) Médecine et médecins au Proche-Orient ancien. Oxford: British Archaeological Reports, 103-19.

Stol, M. (2007) 'Fevers in Babylonia', in Finkel, I. L. and Geller, M. J. (eds.) Disease in Babylonia. Leiden/Boston: Brill, 1-39.

Tseng, W.-S. (2001) 'Culture-Related Specific Syndromes', in Handbook of Cultural Psychiatry. San Diego: Academic Press, 211-63. 
Unschuld, P. U. (2003) Huang Di nei jing su wen: Nature, Knowledge, Imagery in an Ancient Chinese Medical Text, with an Appendix: The Doctrine of the Five Periods and Six Qi in the Huang Di nei jing su wen. Berkeley: University of California Press.

Unschuld, P. U. and Tessenow, H. in collaboration with Z. Jinsheng (2011) Huang Di nei jing su wen: An Annotated Translation of Huang Di's Inner Classic: Basic Questions. 2 Vol. Berkeley: University of California Press.

Van der Toorn, K. (1985) Sin and Sanction in Israel and Mesopotamia: A Comparative Study. Assen: van Gorcum.

Veldhuis, N. (1990) 'The Heart Grass and Related Matters', Orientalia Lovaniensia Periodica $21,27-44$.

Veldhuis, N. (1993) 'The Fly, the Worm, and the Chain: Old Babylonian Chain Incantations', Orientalia Lovaniensia Periodica 24, 41-64.

Veldhuis, N. (2014) History of the Cuneiform Lexical Tradition. Münster: Ugarit-Verlag.

Verderame, L. (ed.) (2011) Demoni mesopotamici. SMSR - Studi e materiali di storia delle religioni 77/2. Brescia: Morcelliana.

Verderame, L. (2017) 'Demons at Work in Ancient Mesopotamia', in Bhayro, S. and Rider, C. (eds.) Demons and Illness from Antiquity to the Early-Modern Period. Boston/ Leiden: Brill, 61-78.

Wasserman, N. (2007) 'Between Magic and Medicine: Apropos of an Old Babylonian Therapeutic Text against the kurārum Disease', in Finkel, I. L. and Geller, M. J. (eds.) Disease in Babylonia. Leiden and Boston: Brill, 40-61.

Wasserman, N. (2012) 'Maškadum and Other Zoonotic Diseases in Medical and Literary Akkadian Sources', Bibliotheca Orientalis 69, 426-36.

Wee, J. Z. (2014) 'Lugalbanda under the Night Sky: Scenes of Celestial Healing in Ancient Mesopotamia', Journal of Near Eastern Studies 73, 23-42.

Wee, J. Z. (2015) 'Discovery of the Zodiac Man in Cuneiform', Journal of Cuneiform Studies 67, 217-33.

Wee, J. Z. (ed.) (2017) The Comparable Body: Analogy and Metaphor in Ancient Mesopotamian, Egyptian, and Greco-Roman Medicine. Leiden/Boston: Brill.

Worthington, M. (2011) 'Serie (Series)', Reallexikon der Assyriologie und Vorderasiatischen Archäologie 12, 395-8.

Young, A. (1976) 'Internalizing and Externalizing Medical Belief Systems: An Ethiopian Example', Social Science \& Medicine 10, 147-56.

Young, A. (1982) 'The Anthropologies of Illness and Sickness', Annual Review of Anthropology 11, 257-85.

\section{Electronic resources}

ETCSL: Black, J. A., Cunningham, G., Ebeling, J., Flückiger-Hawker, E., Robson, E., Taylor, J. and Zólyomi, G. (1998-2006) The Electronic Text Corpus of Sumerian Literature. Oxford (http://etcsl.orinst.ox.ac.uk/).

SEAL: Streck, M. P. and Wasserman. Sources of Early Akkadian Literature (SEAL) (www. seal.uni-leipzig.de/). 